Prepared for the U.S. Department of Energy under Contract DE-AC05-76RL01830

\title{
Technical Needs for Enhancing Risk Monitors with Equipment Condition Assessment for Advanced Small Modular Reactors
}
JB Coble
EJ Berglin
GA Coles
DW Wootan
P Ramuhalli
MR Mitchell

RM Meyer

April 2013

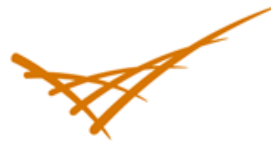

Pacific Northwest

NATIONAL LABORATORY

Proudly Operated by Battelle Since 1965 


\title{
DISCLAIMER
}

This report was prepared as an account of work sponsored by an agency of the United States Government. Neither the United States Government nor any agency thereof, nor Battelle Memorial Institute, nor any of their employees, makes any warranty, express or implied, or assumes any legal liability or responsibility for the accuracy, completeness, or usefulness of any information, apparatus, product, or process disclosed, or represents that its use would not infringe privately owned rights. Reference herein to any specific commercial product, process, or service by trade name, trademark, manufacturer, or otherwise does not necessarily constitute or imply its endorsement, recommendation, or favoring by the United States Government or any agency thereof, or Battelle Memorial Institute. The views and opinions of authors expressed herein do not necessarily state or reflect those of the United States Government or any agency thereof.

\author{
PACIFIC NORTHWEST NATIONAL LABORATORY \\ operated by \\ BATTELLE \\ for the \\ UNITED STATES DEPARTMENT OF ENERGY \\ under Contract DE-AC05-76RL01830 \\ Printed in the United States of America \\ Available to DOE and DOE contractors from the \\ Office of Scientific and Technical Information, \\ P.O. Box 62, Oak Ridge, TN 37831-0062; \\ ph: (865) 576-8401 \\ fax: (865) 576-5728 \\ email: reports@adonis.osti.gov

\footnotetext{
Available to the public from the National Technical Information Service, U.S. Department of Commerce, 5285 Port Royal Rd., Springfield, VA 22161 ph: (800) 553-6847 fax: (703) 605-6900

email: orders@ntis.fedworld.gov online ordering: http://www.ntis.gov/ordering.htm
} 


\title{
Technical Needs for Enhancing Risk Monitors with Equipment Condition Assessment for Advanced Small Modular Reactors
}

\author{
JB Coble EJ Berglin \\ GA Coles DW Wootan \\ P Ramuhalli MR Mitchell \\ RM Meyer
}

April 2013

Prepared for

U.S. Department of Energy

Contract DE-AC05-76RL01830

Pacific Northwest National Laboratory

Richland, Washington 99352 



\section{Abstract}

Advanced small modular reactors (aSMRs) can provide the United States with a safe, sustainable, and carbon-neutral energy source. The controllable day-to-day costs of aSMRs are expected to be dominated by operation and maintenance costs. Health and condition assessment coupled with online risk monitors can potentially enhance affordability of aSMRs through optimized operational planning and maintenance scheduling.

Currently deployed risk monitors are an extension of probabilistic risk assessment (PRA). For complex engineered systems like nuclear power plants, PRA systematically combines event likelihoods and the probability of failure (POF) of key components, so that when combined with the magnitude of possible adverse consequences to determine risk. Traditional PRA uses population-based POF information to estimate the average plant risk over time. Currently, most nuclear power plants have a PRA that reflects the as-operated, as-modified plant; this model is updated periodically, typically once a year. Risk monitors expand on PRA by incorporating changes in the day-by-day plant operation and configuration (e.g., changes in equipment availability, operating regime, environmental conditions). However, population-based POF (or population- and time-based POF) is still used to populate fault trees. Health monitoring techniques can be used to establish condition indicators and monitoring capabilities that indicate the component-specific POF at a desired point in time (or over a desired period), which can then be incorporated in the risk monitor to provide a more accurate estimate of the plant risk in different configurations. This is particularly important for active systems, structures, and components (SSCs) proposed for use in aSMR designs. These SSCs may differ significantly from those used in the operating fleet of light-water reactors (or even in LWR-based SMR designs). Additionally, the operating characteristics of aSMRs can present significantly different requirements, including the need to operate in different coolant environments, higher operating temperatures, and longer operating cycles between planned refueling and maintenance outages. These features, along with the relative lack of operating experience for some of the proposed advanced designs, may limit the ability to estimate event probability and component POF with a high degree of certainty. Incorporating real-time estimates of component POF may compensate for a relative lack of established knowledge about the long-term component behavior and improve operational and maintenance planning and optimization.

The particular eccentricities of advanced reactors and small modular reactors provide unique challenges and needs for advanced instrumentation, control, and human-machine interface (ICHMI) techniques such as enhanced risk monitors (ERM) in aSMRs. Several features of aSMR designs increase the need for accurate characterization of the real-time risk during operation and maintenance activities. A number of technical gaps in realizing ERM exist, and these gaps are largely independent of the specific reactor technology. As a result, the development of a framework for ERM would enable greater situational awareness regardless of the specific class of reactor technology. A set of research tasks are identified in a preliminary research plan to enable the development, testing, and demonstration of such a framework. Although some aspects of aSMRs, such as specific operational characteristics, will vary and are not now completely defined, the proposed framework is expected to be relevant regardless of such uncertainty. The development of an ERM framework will provide one of the key technical developments necessary to ensure the economic viability of aSMRs. 



\section{Acknowledgments}

The work described in this report was sponsored by the Small Modular Reactor Research and Development (R\&D) Program of the U.S. Department of Energy (DOE) Office of Nuclear Energy. The authors gratefully acknowledge Ms. Kay Hass and Ms. Earlene Prickett for their invaluable assistance in the technical editing and formatting of this report. The authors also thank the technical peer reviewers for their feedback and assistance in improving this report. 



\section{Acronyms}

4S

ACT

ARE

aSMR

BOP

CDF

DOE

ECA

$\mathrm{EF}$

EM

EPRI

ERM

FFTF

GCR

GIF

HTGR

$\mathrm{I} \& \mathrm{C}$

ICHMI

LFR

LWR

MOV

MSR

MSRE

$\mathrm{Na}$

NPAR

NPP

NRC

O\&M

ORNL

PHM

POF

PRA

PRISM

PSA

R\&D

RCP

super-safe, small and simple (reactor)

allowed configuration time

Aircraft Reactor Experiment

advanced small modular reactor

balance-of-plant

core damage frequency

U.S. Department of Energy

equipment condition assessment

error factor

electromagnetic

Electric Power Research Institute

enhanced risk monitor

Fast Flux Test Facility

gas-cooled reactor

Generation IV International Forum

high temperature gas-cooled reactor

instrumentation and control

instrumentation, control, and human-machine interface

lead (or lead-bismuth) cooled fast reactors

light-water reactor

motor operated valve

molten salt reactor

Molten Salt Reactor Experiment

sodium

nuclear plant aging research

nuclear power plant

U.S. Nuclear Regulatory Commission

operation and maintenance

DOE Oak Ridge National Laboratory

prognostics and health management

probability of failure

probabilistic risk assessment

Power Reactor Innovative Small Module

probabilistic safety assessment

research and development

reactor coolant pump 
SC-MHR

SCWR

SFR

SMFR

SMR

SSCs

TWR

VHTR steam-cycle modular helium reactor

super critical water reactor

sodium-cooled fast reactor

small modular fast reactor

small modular reactor

systems, structures, and components

traveling wave reactor

very high temperature gas reactor 


\section{Contents}

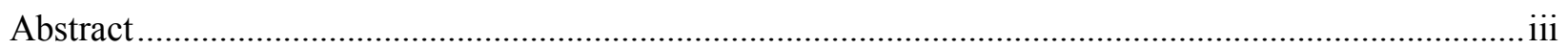

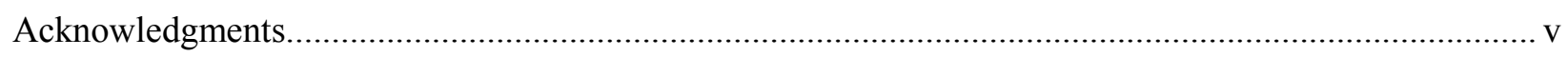

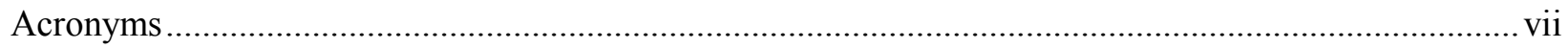

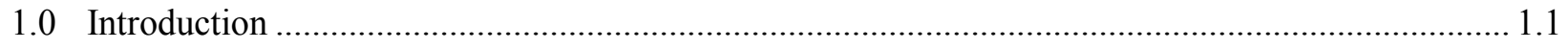

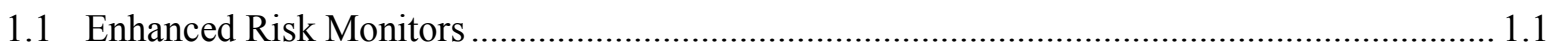

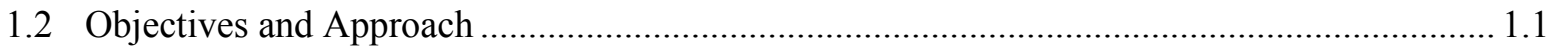

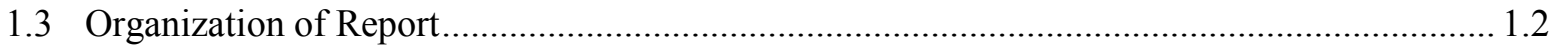

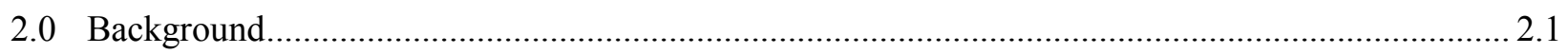

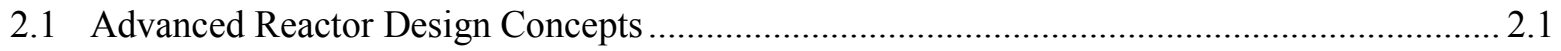

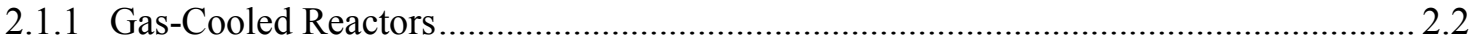

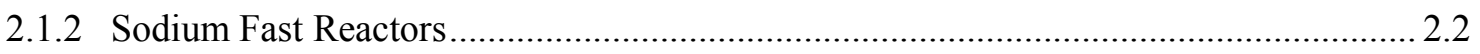

2.1.3 Lead- (or Lead-Bismuth-) Cooled Fast Reactors ...................................................... 2.4

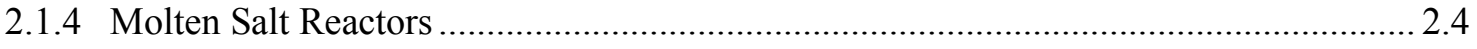

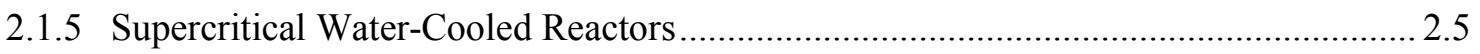

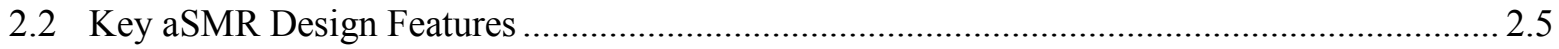

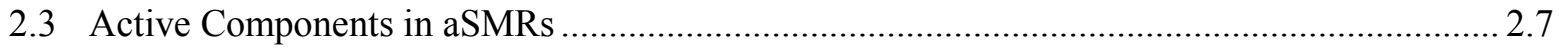

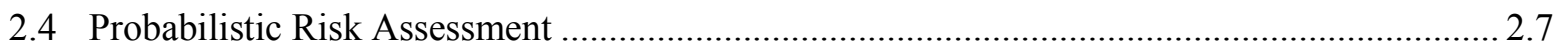

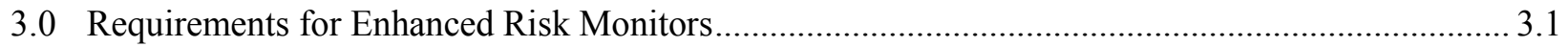

3.1 Integrate Online, Real-Time Equipment Condition Assessment ......................................... 3.2

3.2 Apply to Multiple, Interconnected Modules and Generation Blocks ...................................... 3.3

3.3 Support Reconfigurable Balance-of-Plant and Fluctuating Generation Demands ................... 3.3

3.4 Apply Condition-Specific Fault Trees, Event Trees, and Success Criteria............................. 3.3

3.5 Evaluate Multiple Risk Measures ….................................................................................... 3.4

3.6 Evaluate Risk over Multiple Time Horizons............................................................................ 3.4

3.7 Meet Runtime Requirements for Control and O\&M Planning .............................................. 3.4

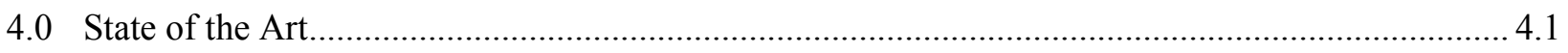

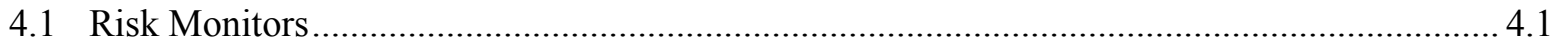

4.2 Equipment Condition Assessment …........................................................................ 4.1

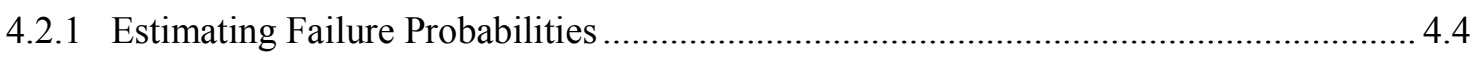

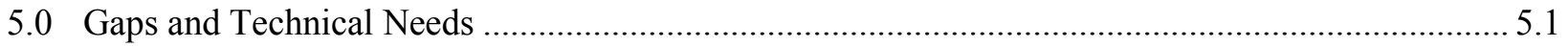

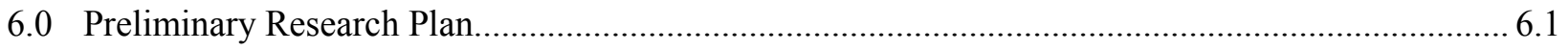

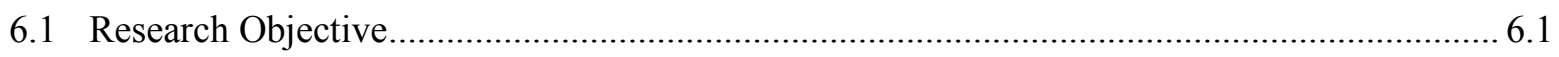

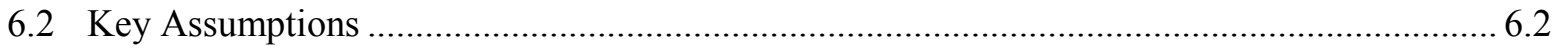

6.3 Development of Conceptual ERM Framework ................................................................. 6.3

6.3.1 Identify Appropriate Risk Measures for aSMRs ...................................................... 6.4

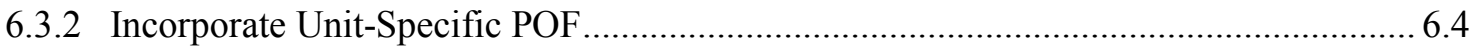




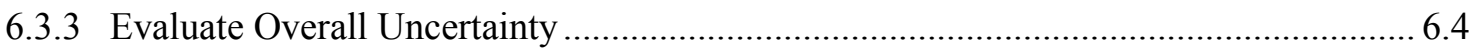

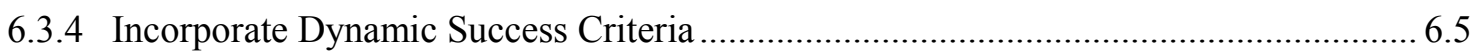

6.3.5 Incorporate ERM Results in Supervisory Control and O\&M Planning ........................ 6.5

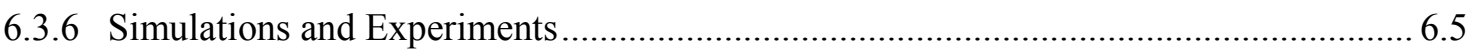

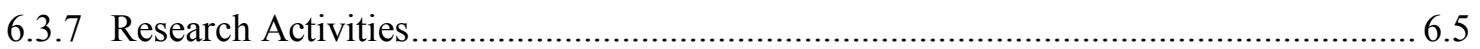

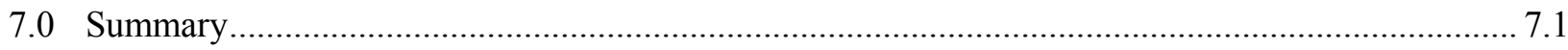

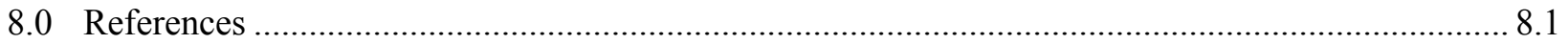




\section{Figures}

2.1 In Proposed aSMRs, Multiple Reactor Modules may be Co-located to Support Common Electrical Generation and Process Heat Applications.............................................................. 2.6

3.1 ERMs Can Provide Greater Situational Awareness to the Plant Supervisory Control and

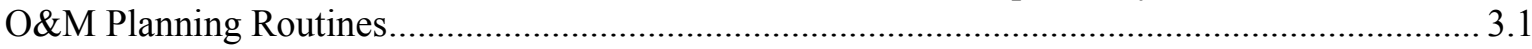

3.2 Features Inherent to aSMR Designs Lead to a Number of Requirements for ERMs .................... 3.2

4.1 Equipment Condition Assessment Routines and Prognostic Models can be used to Evaluate the POF at Time $t_{i}$ Given the Expected Stresses ....................................................................... 4.4

6.1 Considerations and Steps to Achieving an Enhanced Risk Monitor............................................. 6.2

6.2 A Single Generation Block in the Proposed aSMR Plant Configuration........................................ 6.3

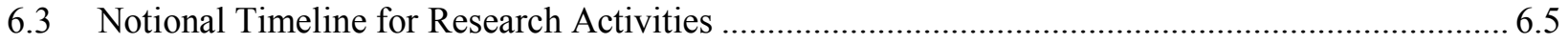

\section{Tables}

4.1 Example Equipment Condition Assessment Methods for Selected Active Components in

4.2 Selected Prognostic Algorithms for Active Components 4.6 



\subsection{Introduction}

Advanced small modular reactors (aSMRs), which are based on modularization of advanced reactor concepts, may provide a longer-term alternative to traditional light-water reactors (LWRs) and small modular reactors (SMRs) based on integral pressurized water reactor concepts currently being advanced. aSMRs are conceived for applications in remote locations and for diverse missions that include providing process or district heating, water desalination, and hydrogen production. The controllable day-to-day costs of aSMRs are expected to be dominated by operation and maintenance (O\&M) costs. Health and condition assessment coupled with online risk monitors can potentially ensure affordability of aSMRs through optimized operation planning and maintenance scheduling. Incorporation of condition knowledge into operational risk monitors can enable real-time decisions about stress relief for susceptible equipment while supporting effective maintenance planning.

\subsection{Enhanced Risk Monitors}

Risk monitors are intended to provide a point-in-time estimate of the system risk given the current plant configuration (e.g., equipment availability, operational regime, environmental conditions). However, current risk monitors are limited in that they do not take into account plant-specific normal, abnormal, and deteriorating states of active components and systems. The ability to incorporate unitspecific estimates of the probability of failure (POF) by utilizing real-time or near-real-time condition knowledge of the key systems, structures, and components (SSCs) into dynamic probabilistic risk assessment (PRA) has the potential to enable real-time decisions about stress relief and support effective maintenance planning while ensuring investment protection. Such enhanced risk monitors (ERMs) are expected to improve the safety, economy, and availability of aSMRs.

ERMs will support the economic goals of aSMRs by providing a tool for optimizing operations and maintenance activities. To ensure safety and optimize the economics of aSMRs, asset management and asset optimization are particularly important. Online testing or maintenance actions can support shorter outages and longer periods of power generation between outages; this may necessitate changes of the plant or module configuration during normal operation. Advanced plant configuration, condition, and risk monitors are needed to support frequently changing plant configurations (Yoshikawa et al. 2011). Asset optimization through ERMs will improve economics of aSMRs by:

- Maximizing generation by assessing the potential impact of taking key components offline for testing or maintenance,

- Supporting reduced operations and maintenance staff by aiding in optimization of O\&M planning, and

- Supporting potential remote siting by providing early warning of potential increases in plant risk.

\subsection{Objectives and Approach}

This report focuses on the technical gaps in development of ERMs for active components in aSMR designs by integrating real-time information about equipment condition and POF into the risk monitor framework. This report also documents a number of requirements for enhanced risk monitors that integrate real-time estimates of equipment condition. These requirements are derived from expected 
operational characteristics of proposed aSMRs. An evaluation of available literature was used to identify proposed concepts for aSMRs along with likely operational characteristics. Along with current approaches to risk monitors, these were used to define a set of requirements for ERM. Likely active components in these concepts were also identified and used to quantify the state of the art in equipment condition assessment. This assessment, combined with the requirements, was used to identify technical gaps in the development, assessment, and deployment of ERMs for aSMRs.

\subsection{Organization of Report}

This document is organized as follows. Section 2 describes an overview of advanced SMRs and probabilistic risk assessment. Section 3 describes the requirements for ERM. Section 4 presents the state of art in risk monitors and their use in current light-water reactors, as well as the state-of-art in equipment condition assessment. This is followed by an assessment of the gaps in realizing ERM (Section 5) and a preliminary research plan to address high-priority gaps (Section 6). Section 7 summarizes the findings and describes the next steps. 


\subsection{Background}

Health monitoring techniques can be used to establish condition indicators and monitoring capabilities that serve to indicate the risk posed by continued operation in the presence of detected degradation. This is particularly important for SSCs proposed for use in aSMR designs. These SSCs may differ significantly from those used in the operating fleet of light-water reactors (or even in LWR-based SMR designs). The relative lack of operating experience for some of these SSCs may limit the ability to estimate event probability and component POF to a high degree of certainty. Incorporating real-time estimates of these probabilities that are based on equipment condition assessments may help compensate for a relative lack of knowledge about the long-term component behavior.

However, the operating characteristics of proposed aSMR designs impose challenges to real-time equipment condition assessment. Several aSMR concepts utilize pool-type or integral configurations or very compact arrangements, which reduces accessibility to key active components. These designs are also expected to have fewer offline component testing and maintenance opportunities due to longer operating cycles between refueling. Condition monitoring would provide condition indicators for key active equipment using online, in-situ sensors and measurements to support detection and identification of incipient failure and to reflect evolving degradation.

aSMR designs are distinguished from other nuclear power plant (NPP) designs - (1) utilizing nonlight water coolants, (2) deliberately small in size, and (3) potentially modular in configuration and operation. Coolants being proposed include liquid sodium, lead or lead-bismuth eutectic, helium, and molten salt. The following section summarizes the major advanced reactor concepts, including gas-, liquid metal-, lead-, molten salt-, and supercritical water-cooled reactors. Although the vast majority of NPP operating experience involves light-water-cooled reactors, there is some experience with select advanced reactors, which is also summarized to identify potential faults and failure modes for key active components. Some of these issues are expected to be resolved in the new aSMR designs (e.g., moisture intrusion through water-lubricated bearings may be avoided by using magnetic bearings); however, other issues may still be relevant. These issues are likely to drive monitoring and maintenance requirements in future advanced reactors.

Following this overview of advanced reactor concepts and experience, features specific to the small, modular nature of aSMRs are described, with a focus on those facets that are likely to motivate the use of ERMs.

\subsection{Advanced Reactor Design Concepts}

Leading aSMR designs are based on the advanced reactor concepts identified by the Generation IV International Forum (GIF) (Abram and Ion 2008): Gas Cooled Reactors (GCRs), Sodium-Cooled Fast Reactors (SFRs), Lead- (or Lead-Bismuth-) Cooled Fast Reactors (LFRs), Molten Salt Reactors (MSRs), and Super Critical Water Reactors (SCWRs). With the exception of SFRs and GCRs, limited experience has been accumulated with respect to operation of advanced reactors. The following sections summarize the generic features of the advanced reactor concepts and the available operating experience related to active components in advanced reactors. 


\subsubsection{Gas-Cooled Reactors}

GCR systems feature either thermal or fast-neutron-spectra. The main characteristics of the GCR utilizing fast-neutron-spectra are: a self-generating core (i.e., conversion ratio $=1$ ) with a fast neutron spectrum, robust refractory fuel, high operating temperature, and potential direct energy conversion through He Brayton cycle. The thermal reactor variant is similar in design but incorporates moderators to thermalize the neutrons. These reactors typically have no engineered active safety features and require no operator action to ensure safety. Variants of GCRs include high-temperature gas-cooled reactors (HTGR) and very high temperature gas-cooled reactors (VHTR). In principle, either the fast or thermal GCR could have a direct cycle (Brayton cycle turbine) or an indirect cycle with heat exchangers, steam generators, and secondary fluid for power conversion. The VHTR has been proposed with a direct heat cycle.

GCR designs use loop-type reactor vessel configurations, meaning minimal equipment is located in the reactor vessel. Active components and systems in GCRs include:

- Control rod mechanisms - Drives located outside reactor vessel with rod extending into vessel. May be both control and shutdown rods.

- Gas circulator - Circulates primary helium.

- Turbine/Compressor - Provides forced cooling during normal operation. Separate unit connected to reactor vessel via piping. Under pressure during operation. Turbine and compressor are motordriven during startup and shutdown.

- Pumps - Primarily associated with secondary cooling heat exchangers and interface with turbine/compressor unit.

- Valves - Located outside of reactor vessel.

Operating history of HTGRs highlights potential problems with active components in GCRs. Intrusion of oil, water, and other contaminants into the coolant system was a problem at HTGR plants. The use of water-lubricated bearings in helium circulators at Fort St. Vrain plant led to moisture intrusion, which contributed to corrosion in an otherwise non-corrosive environment (McDowell et al. 2011). Oil leakage through the compressor at Peach Bottom 1 plant resulted in approximately $100 \mathrm{~kg}$ of oil in the reactor (Beck et al. 2010). These contaminants contributed to issues with the control rod drive mechanisms, including mechanical jamming that prevented rod insertion (Beck et al. 2010).

\subsubsection{Sodium Fast Reactors}

The SFR features very high core power densities, high reactor outlet temperatures, low system pressure, and a fast neutron spectrum. An advantage of sodium coolant is its relatively high heat capacity, which protects against overheating during reactor transients and accidents. While the fast neutron spectrum results in large fluences for internal core and reactor vessel components, it also enables fissile and fertile materials to be used considerably more efficiently than thermal spectrum reactors with oncethrough fuel cycles. Some of the SFR designs, like the Super-Safe, Small \& Simple (4S) reactor and unique traveling wave reactor (TWR), are optimized for power generation over long periods of time (10-40+ years) without refueling. 
The primary coolant system can either be arranged in a pool layout (a common approach, where all primary system components are housed in a single vessel), or in a compact loop layout (favored in Japan). Domestic SFR designs (e.g., Power Reactor Innovative Small Module [PRISM], TWR) use a pool-type reactor vessel design containing the reactor core, primary heat exchanger, and electromagnetic (EM) pump(s). The Japanese $4 \mathrm{~S}$ reactor design utilizes a reactor vessel with a loop design (similar to the Fast Flux Test Facility [FFTF]) containing just the reactor core; the primary heat exchanger(s)/pumps are connected by piping to the reactor vessel. An inert cover gas system is used to prevent sodium exposure to air and/or water and to support the reactor vessel, reactor containment vessel, heat exchangers, and steam generator. Under accident conditions, complete passive cooling of the reactor vessel is available through natural convection in the primary loop with air blowers cooling a sodium-air heat exchanger. In general, all penetrations into the reactor vessel occur at the top of the vessel.

Although there are several SFR designs, the general design and operating parameters are similar. The long refueling reactors (such as $4 \mathrm{~S}$ and TWR) on the order of 20-40+ years will require long-life components with the hope that routine maintenance is limited. The shorter refueling reactors (such as PRISM) on the order of 1.5+ years require fuel exchange operations that likely will allow some minimal maintenance to be performed. EM pumps are generally used to pump liquid sodium. Most designs are opting to use a helical coil steam generator design. The $4 \mathrm{~S}$ reactor uses a unique reactive control mechanism.

Active features in SFRs that may be risk-significant include:

- Reactor control mechanisms - Drives located outside reactor vessel with rod extending into vessel. May be both control and shutdown rods. May be very slow movement over long time periods.

- Pumps - Pumping fluids/gas to various reactor systems including heat exchanger (2 loops), cover gas, and turbine/compressor unit. Sodium pumps in reactor vessel are typically EM pumps with no moving parts.

- Heaters - Inside and outside reactor vessel. Heat is required to liquefy sodium during initial startup and maintenance periods. In many cases, this may look like a passive device.

- Turbine/compressor - Separate unit connected to steam generator via piping. Under pressure during operation.

- Valves - Outside of reactor vessel. May include dampers on air circulators.

- Fuel handling mechanisms - For reactors with temporary fuel storage in reactor vessel.

A review of the operating experience of SFRs reveals problems with mechanical sodium pumps, EM sodium pumps, valves, and instrumentation. Mechanical sodium pumps suffered from pump failures related to pump vibration, flow imbalance among pumps, the supply and speed regulation system, and oil ingress through the upper bearing (Guidez et al. 2008). The EM sodium pumps at FFTF also experienced problems, largely due to cavitation erosion at low flow rates (Baumhardt and Bechtold 1987).

Manufacturing defects in valves led to sodium leaks at the Fast Breeder Test Reactor (Guidez et al. 2008). Instrumentation failures at Experimental Breeder Reactor-II, Phenix, and Superphenix were largely compensated for by redundancy in the original instrumentation and control (I\&C) design and the use of substitute instruments (Guidez et al. 2008). 


\subsubsection{Lead- (or Lead-Bismuth-) Cooled Fast Reactors}

The LFR system features the potential for a very high reactor outlet temperature, high power density core, low system pressure, and a fast neutron spectrum. The liquid metal coolant, either lead $(\mathrm{Pb})$ or lead/bismuth eutectic ( $\mathrm{Pb}-\mathrm{Bi}$ ) can utilize natural convention for heat removal or can be pumped, depending on core power requirements. Some LFR designs for small grids or developing countries, like the Gen4 and SSTAR (small, secure, transportable, autonomous reactor), use a factory-built "battery" or "cassette" design and are optimized for power generation over long periods of time (10-30 years) without refueling.

Potential issues with lead-cooled technologies arise from the solidification of the coolant, which can render the reactor inoperable. Lead is the heaviest of all proposed advanced coolants, making it expensive to pump. Additionally, coolant chemistry can lead to erosion of pump materials. Unlike other advanced designs, mechanical pumps are generally proposed for use in LFRs, because EM pumps have low efficiency moving lead.

Additional active features of LFRs include:

- Reactor control mechanisms - Control rod drive mechanisms are located outside the reactor vessel with rods extending into vessel. The Gen 4 Module also includes insertion of boron carbide $\left(\mathrm{B}_{4} \mathrm{C}\right)$ balls into a cavity for shutdown.

- Pumps - Pumping fluids/gas to various reactor systems, depending on the reactor design. The SVBR-100 (Svintsovo-Vismutovyi Bystryi Reaktor) reactor utilized pumps for primary lead coolant, where other design like STAR (Secure Transportable Autonomous Reactor) series, BREST-OD-300 reactor use natural convection and have no primary coolant pumping.

- Valves - Primarily located outside of reactor vessel.

- Instrumentation and monitoring systems, including system for monitoring dissolved oxygen in lead coolant (used to limit corrosions on structural surfaces by coolant), cover gas monitoring system, and delayed neutron detection.

Literature reviewed indicated that the only lead-bismuth cooled reactors with significant operating experience were the ones installed in Russian Alpha-class submarines and the prototype reactors that supported them - seven submarines and two prototypes (Weaver et al. 2001). Flow measurements were made by electromagnetic devices, but these were unreliable due to calibration shifts; however, a venturitype flow meter operated successfully for 15 months without calibration drift (Woloshun et al. 2004).

\subsubsection{Molten Salt Reactors}

The MSR features high reactor outlet temperatures, low system pressure, and in some variants a fluidfueled core where the molten salt coolant contains dissolved fuel that allows for refueling without reactor shutdown. This reactor type can be designed to operate with either a thermal or fast neutron flux and has the unique characteristic that, in theory, very high fuel burnup can be achieved because fuel performance in the fluid-fueled concepts is not limited by fuel cladding strength and ductility considerations. The liquid-fueled MSRs can be used for electricity generation, actinide burning, and hydrogen and fissile fuel production. 
MSR designs incorporate several active components that have been identified as potential degradation concerns. The entire primary loop is extremely radioactive and operates at high temperatures compared to conventional LWR designs; the primary fuel salt system needs fully remote operation and maintenance for components such as primary pumps. Some designs, such as Fiji MSR, propose centrifugal pumps for the primary system (Adamovich et al. 2007). Additionally, valves in the primary system may suffer from fusion bonding with molten salt (NERAC 2002). Liquid-fueled MSRs feature a fuel/coolant exchange system which removes waste products from the fuel salt and adds in fresh fuel as the reactor is operating; operational concerns related to this system have not been reported.

Two molten salt reactors were operated at Oak Ridge National Laboratory (ORNL) between 1954 and 1969. The first of these was the Aircraft Reactor Experiment (ARE), intended to prototype a molten salt reactor to provide propulsion for large aircraft (typical of the B-36) by an indirect cycle (Rosenthal 2009). ARE operated for 9 days in 1954, no mechanical or chemical problems were encountered, and the reactor was stable and self-regulating (Rosenthal et al. 1970). The second, larger reactor operated from 1965 to 1969, and was called Molten Salt Reactor Experiment (MSRE) (Rosenthal 2009). MSRE operated from October 1968 to the end of the experiment in December 1969, during which time it had no significant operational problems (MacPherson 1985).

\subsubsection{Supercritical Water-Cooled Reactors}

The SCWR is a high-temperature, high-pressure water cooled reactor that operates above the thermodynamic critical point of water. The reactor operates at much higher temperatures and pressures resulting in higher operating efficiencies (44\% compared to $32 \%$ in current LWRs). These reactors can be designed to operate with either a thermal or fast-neutron spectrum, providing flexibility in deployment and generation options. Additionally, the energy conversion technology associated with the secondary side of the reactor plant has been fully developed and commercialized by the coal fire industry over the last several decades.

SCWR eliminates several major components, such as steam dryers, recirculation pumps, and steam generators. Active components expected to contribute to risk include control rod drive mechanisms, pumps, and valves. Like many designs, the control rod drive mechanism is located outside the reactor vessel, with rods inserted vertically into the core (Duffey and Pioro 2005). Pumps in SCWR operate at speeds as low as eight times slower than those in current PWRs because of the high thermal capacity of supercritical water (Duffey and Pioro 2005; Reiss et al. 2010).

\subsection{Key aSMR Design Features}

Small modular reactors (SMRs) generally include reactors with electric output of $\sim 350$ MWe or less (this cutoff varies somewhat but is substantially less than full-size plant output of $700 \mathrm{MWe}$ or more). aSMRs refer to a specific class of SMRs and are based on modularization of advanced reactor concepts. SMRs (whether light-water cooled or based on advanced reactor concepts) are designed to incorporate multiple modules (which may or may not have shared components and structures) at a single location, comprising a full "plant." SMR operation differs fundamentally from full-size plants because the smaller plants may be used for load-following or peak-demand power generation, instead of baseload generation. SMRs are also being considered for dual-use, where process heat would be used for both electricity generation and another purpose such as hydrogen production or water desalination, shown in Figure 2.1. 
These operating characteristics will likely impact the ability to apply conventional PRA and risk monitors.

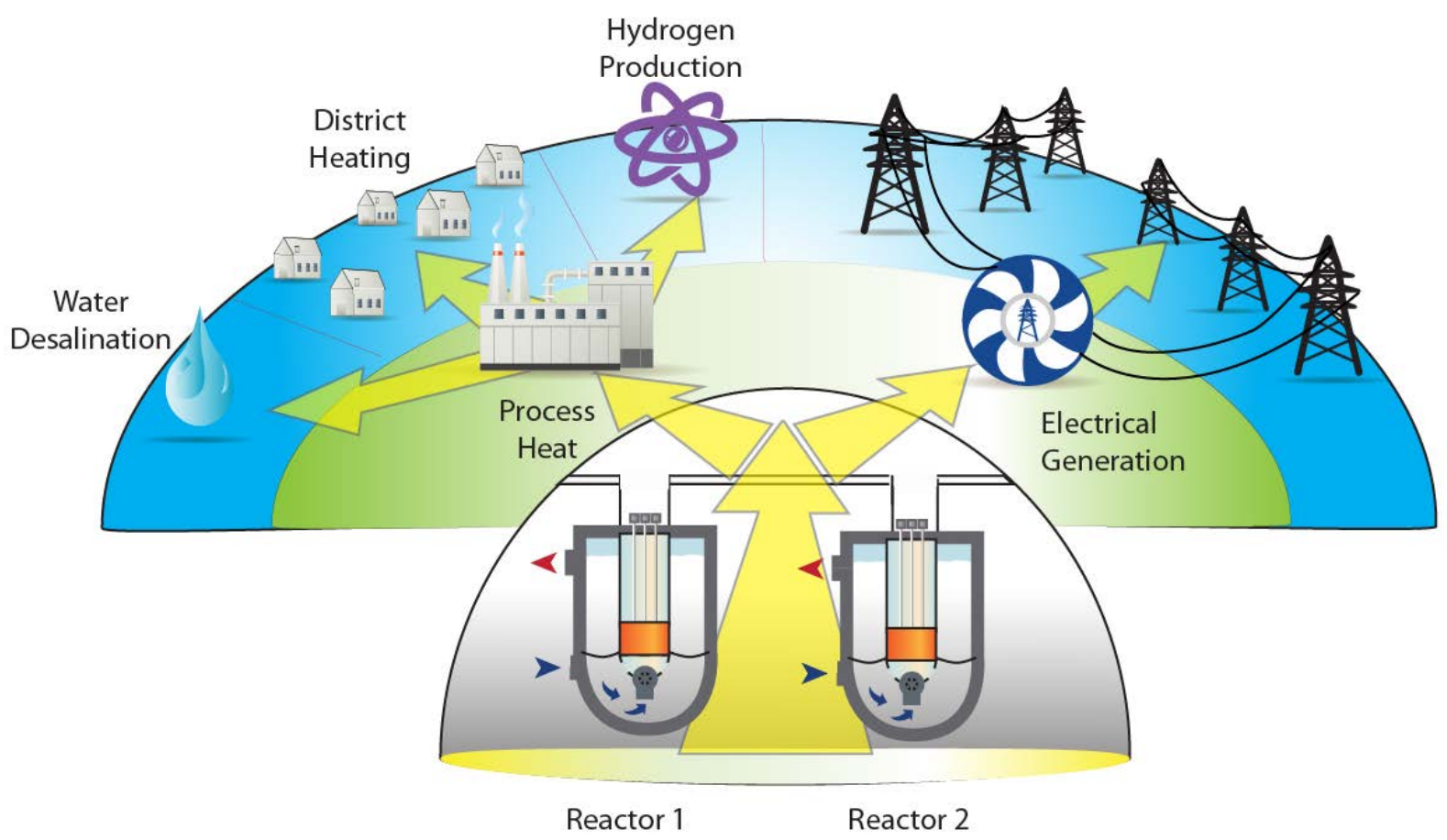

Figure 2.1. In Proposed aSMRs, Multiple Reactor Modules may be Co-located to Support Common Electrical Generation and Process Heat Applications

Taken together, the particular eccentricities of advanced reactors and small modular reactors provide unique challenges and needs for advanced instrumentation, control, and human-machine interface (ICHMI) techniques in aSMRs. Several features of aSMR designs increase the need for accurate characterization of the real-time risk during operation and maintenance activities. These include:

- Reduced accessibility, possibly due to pool-type designs with submersed components, sealed systems to improve proliferation resistance, or remote siting;

- Reduced redundancy of active components and systems, possibly due to greater reliance on passive systems;

- Potential multi-modular operation, which may introduce interconnections or dependencies between SSCs in reactor modules and generation blocks (multiple reactor modules connected to common balance-of-plant (BOP) systems, such as the power blocks proposed for the PRISM reactor);

- New operating regimes, including potential load-following and peak-demand power generation;

- Potential use for applications beyond electricity production (e.g., water desalination, hydrogen production, process heat applications); and

- Longer periods between inspection opportunities due to longer operating cycles and reduced O\&M staff. 


\subsection{Active Components in aSMRs}

Active components in NPPs include those components whose parts must move to fulfill their operational goals; these components such as pumps, motors, generators, sensors, and control rod drive. The relevant operating experience for active components in advanced reactors is described in Section 2.1. Common themes and issues that have been seen across the spectrum of advanced reactor designs or are expected in aSMRs are summarized here.

Advanced SMRs will likely rely on passive mechanisms to achieve safety goals. This may include reliance on thermal convection or gravity for coolant circulation and/or decay heat removal through natural processes. However, a number of active components (e.g., coolant pumps, compressors, circulators) are needed for reliable operation, and some systems with safety-related functions rely on active components, such control rod drive latch mechanisms. Additionally, some non-safety but potentially risk-significant systems require active components for initiation of passive features. For example, the PRISM Auxiliary Cooling System (ACS), which supports shutdown heat removal, is initiated by opening of inlet and outlet louvers in the steam generator building. For the ACS to operate effectively, these louvers must be opened to allow natural circulation of air-cooling of the steam generators and circulation of sodium in the intermediate loop (NRC 1994). Because core damage frequency (CDF) for aSMRs could be one to two (or more) orders of magnitude lower than for currently operating nuclear power plants due to these passive features, the relative risk importance of active systems can increase because the POF of passive systems is low. Because of inexperience in operating aSMR design, understanding the impact of active component failure on passive safety system failure modes and vice versa could be important. Failure mode analysis, if available, is expected to be useful in the construction of risk monitors.

aSMR designs feature advanced component designs (e.g., magnetic pumps and bearings) to increase safety, enhance the ability to withstand harsh environments, and improve plant availability and generation. Operating experience and well-developed models of component performance may not be available for these new designs, especially for the estimation of failure probabilities in the potentially harsh environment of an aSMR. This makes component health assessment and integration with PRA and risk monitors even more important to provide an accurate, online assessment of risk associated with normal operation and maintenance activities.

\subsection{Probabilistic Risk Assessment}

PRA (also called probabilistic safety assessment - PSA) gained favor in the nuclear power industry following the Reactor Safety Study commissioned by the U.S. Nuclear Regulatory Commission (NRC) and the accident at Three Mile Island. In general, risk can be defined as the product of the frequency of an event and its consequence:

$$
\text { Risk }=\text { Frequency } \times \text { Consequence }
$$

where Consequence refers to undesirable outcomes (reactor core damage, release frequency of radionuclides, cancer deaths) and Frequency is the likelihood of the consequence per unit time. 
In the nuclear industry, risk is typically evaluated for events that have consequences related to public health and safety. The assessment of risk with respect to nuclear power plants is intended to achieve the following general objectives (Fulwood and Hall 1988):

- Identify initiating events and event sequences that might contribute significantly to risk;

- Provide realistic quantitative measures of the likelihood of the risk contributors;

- Provide a realistic evaluation of the potential consequences associated with hypothetical accidents; and

- Provide a reasonable risk-based framework for making decisions regarding nuclear plant design, operation, and siting.

Three levels of PRA, designated by the type of risk being assessed, have been considered for NPPs (NRC 2012). Level 1 PRA estimates the frequency of accidents that cause core damage (commonly called core damage frequency); Level 2 PRA, the frequency of radioactive release from the NPP (assuming that the core is damaged); and Level 3, the consequences to the public and environment outside the NPP due to Level 2 radioactive releases. The ultimate result of the PRA is the probability of each undesirable consequence (e.g., core damage, radioactive release) and a list of the major contributors to its occurrence.

PRA is a systematic safety analysis methodology that follows four steps (Haasl et al. 1988; Apostolakis 2000): (1) identify undesirable consequences (e.g., reactor unavailability, core damage, release of radioactivity) and initiating events that can lead to these consequences; (2) systematically identify accident sequences [defined by event trees (Papazoglou 1998) and fault trees (Vesely et al. 1981)] through which the facility can move from the initiating event to the undesired consequence; (3) calculate the probability of occurrence for each accident sequence; and (4) rank the accident sequences according to probability of occurrence (or, alternatively, contribution to the undesirable event) to manage the major contributors to risk. As PRA models are integrated into plant management, they have become living models that reflect the as-modified and as-operated plant configuration and are able to estimate the changing likelihood of undesired events.

Uncertainty in PRA modeling arises from a number of sources that are typically divided into aleatory variability and epistemic uncertainty. Aleatory variability is related to the statistical confidence we have in failure probability data, while epistemic uncertainty is related to the uncertainty in the accident sequences used to develop the PRA model. Epistemic uncertainty is dealt with by developing event and fault trees as complete as possible, identifying keys sources of uncertainty, and performing sensitivity analyses. The aleatory variability is addressed explicitly by propagation of parametric data uncertainty for initiating basic event data. The nuclear power industry has gathered and compiled component failure and event data to support propagation of parametric data uncertainty. Much of the nuclear industry's component failure data uncertainty is expressed as a lognormal (or normal) probability distribution with specified errors factors (EFs) that define the 10th and 90th percentile of the probability distribution. Uncertainty analysis is performed through a sampling strategy (e.g., Monte Carlo sampling) over some number of observations. 
Risk monitors extend the PRA framework by incorporating the actual and dynamic plant configuration (e.g., equipment availability, operating regimes, environmental conditions) into the risk assessment. The ERM will further extend this analysis by incorporating equipment condition into a more accurate estimate of the probability of component failure. In addition to accommodating these component-specific POF, application to aSMRs will impose additional requirements on the ERM because of the unique concepts of operation. The following section outlines the functional requirements necessary to apply ERM to aSMRs. 



\subsection{Requirements for Enhanced Risk Monitors}

Risk monitors are intended to provide a point-in-time estimate of the system risk given the current plant configuration. Current risk monitors are limited in that they do not properly take into account the normal, abnormal, and deteriorating states of plant equipment, which are unit-specific. Current approaches to computing risk monitors use PRA techniques that have been used in U.S. NPPs to assess the risks associated with operation since the 1980s (Wu and Apostolakis 1992). PRA systematically combines the event probability and POF for key components to determine the hazard probability for subsystems and the overall system (Kafka 2008). In general, PRA estimates use a static estimate for event probability and POF. This estimate is typically made based on historic observations and engineering judgment. More recently, time-based POF values have been incorporated in so-called living PRA (Arjas and Holmberg 1995). These time-based POF values are derived from operating experience and traditional reliability analysis; they are not specific to the operating component. The ability to incorporate unit-specific estimates of the POF, by using real-time or near-real-time condition knowledge of the equipment into operational risk monitors has the potential to enable real-time decisions about stress relief for susceptible equipment while supporting effective maintenance planning (Figure 3.1).

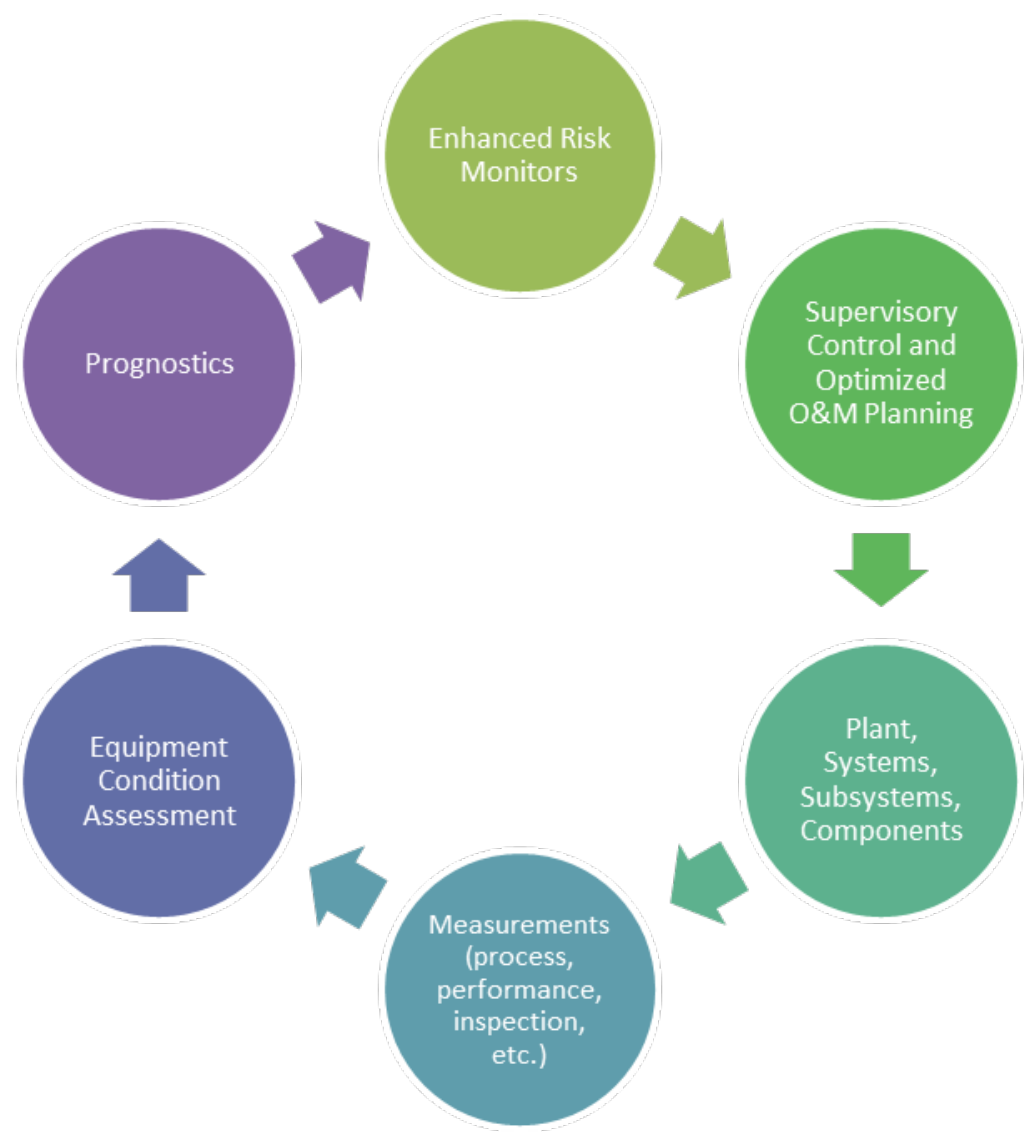

Figure 3.1. ERMs Can Provide Greater Situational Awareness to the Plant Supervisory Control and O\&M Planning Routines 
ERMs that incorporate real-time estimates of the condition of active SSCs are expected to improve the safety, economics, and availability of aSMRs. Enhanced risk monitors will support the economic goals of aSMRs by providing a tool for optimizing operations and maintenance activities. Features of aSMRs inform the functional requirements for enhanced risk monitoring, summarized in Figure 3.2. This section provides details of the functional requirements.

\begin{tabular}{|c|c|}
\hline aSMR Features & ERM Requirements \\
\hline $\begin{array}{l}\text { Reduced accessibility } \\
\text { pool-type designs } \\
\text { sealed systems } \\
\text { remote siting } \\
\text { Reduced active component } \\
\text { redundancy } \\
\text { New component designs } \\
\text { New concepts of operation } \\
\text { multi-modular operation } \\
\text { fluctuating generation demands } \\
\text { new generation missions } \\
\text { potential co-generation } \\
\text { Longer periods between inspection } \\
\text { and maintenance opportunities }\end{array}$ & 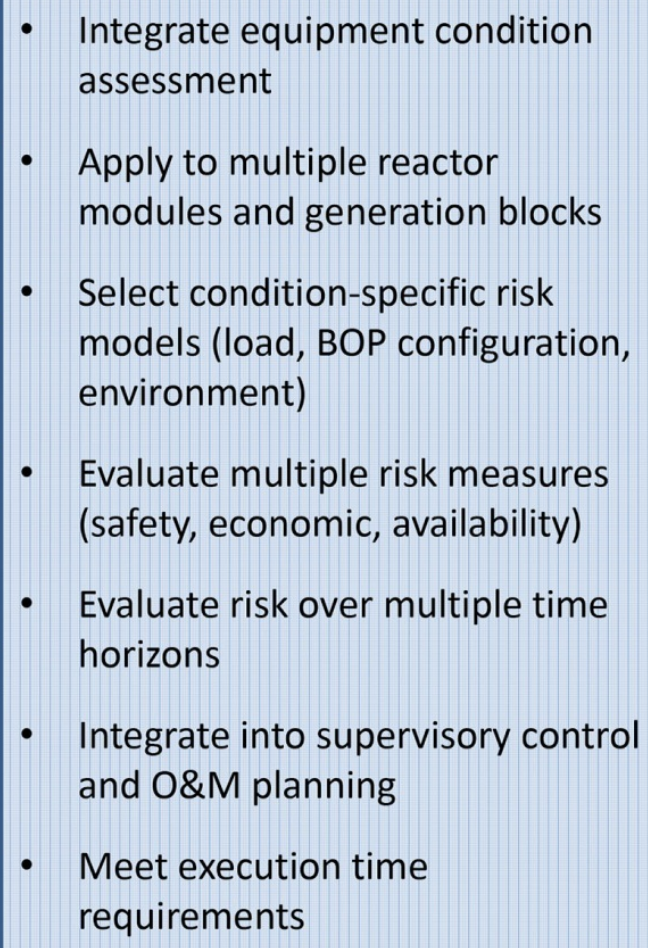 \\
\hline
\end{tabular}

Figure 3.2. Features Inherent to aSMR Designs Lead to a Number of Requirements for ERMs

\subsection{Integrate Online, Real-Time Equipment Condition Assessment}

Population-based estimates of component and system reliability ignore the unit-specific variation due to factors such as manufacturing, maintenance actions, and operating conditions. Equipment condition assessment (ECA) can provide a real-time estimate of the reliability POF of a specific component, both instantaneous and over some specified time horizon. These POF estimates give a more realistic view of the component, system, module, and plant risks. ERMs must integrate online equipment condition assessment results where they are available. These estimates, though more accurate than populationbased reliability values, will have some level of uncertainty associated with them. ERMs must use the ECA results and associated uncertainty to provide a realistic, actionable measure of risk with its associated uncertainty. 
By incorporating an accurate assessment of component condition in the risk assessment, aSMR operations and maintenance can be optimized to provide the greatest possible generation and availability while minimizing the actual plant risk. Without ERMs, a significant level of conservatism will likely be required to provide high confidence in operating plants, which will negatively impact the economics of operating and maintaining aSMRs.

\subsection{Apply to Multiple, Interconnected Modules and Generation Blocks}

Many aSMR designs feature multiple reactor modules connected to common generation components (e.g., turbine generators, process heat lines). Conditions in one module may affect the risk in another module through these shared components. ERMs will need to consider reactor modules and secondary systems as an integrated system to understand and account for module dependencies. Additionally, ERMs for multi-modular aSMRs may need to account for the possibility of common cause failures for components across modules and the resulting effect on plant availability. Condition assessment could address the potential for common cause failure more explicitly than current PRA and risk monitors. Inability to account for interconnected systems will likely increase the amount of conservatism.

\subsection{Support Reconfigurable Balance-of-Plant and Fluctuating Generation Demands}

Multi-modular plants can control the output of each reactor module and generation block depending on demand, mission, and condition of the module. ERMs must be able to account for frequently changing demands and load mismatch across multiple (possibly interconnected) reactor modules and across the generation blocks. The alternative is an inaccurate assessment of plant risk under a variety of BOP configurations and generation demands, consequently reducing the amount of flexibility available to aSMR operations.

Additionally, aSMR designs can support diverse missions, such as electricity production, water desalination, shale oil extraction, and even cogeneration (e.g., process heat for both electricity production and water desalination). In plants with cogeneration, the BOP will effectively be reconfigured depending on the current generation mission. ERMs must be able to account for changing BOP configurations, both at the current time and projected through some time horizon, to accurately evaluate the overall plant risk.

\subsection{Apply Condition-Specific Fault Trees, Event Trees, and Success Criteria}

As the load on a single module and/or across the plant fluctuates and the BOP is reconfigured, the change in success criteria must be reflected in the fault trees and event trees. For instance, a module operating at $100 \%$ power may require faster control rod insertion or insertion of more control rods to reach a safe state than a module operating at $50 \%$ power. Conversely, a module operating at $50 \%$ power may require sufficiently less cooling than a module at $100 \%$ power, and a cooling configuration not successful at $100 \%$ power may become successful at $50 \%$ power. The ERMs must consider the current operating loads, environmental conditions of modules, and the full plant to apply appropriate event 
sequences. Without the flexibility to incorporate appropriate load information, the ERMs will likely have to evaluate a "worst-case scenario," resulting in an artificially inflated estimate of the risk.

\subsection{Evaluate Multiple Risk Measures}

ERMs can support many goals of aSMRs, including safety goals, economic goals, and generation goals. Traditional PRA risk measures (e.g., core damage frequency, large early release, off-site dose consequences) may be appropriate for monitoring safety goals, but new risk measures may be needed for economic and generation goals (e.g., availability, reliability, probability of mission completion). Without these additional risk measures, the ERMs may not provide the information necessary for optimized O\&M planning or supervisory control algorithms, reducing the utility of the ERMs.

\subsection{Evaluate Risk over Multiple Time Horizons}

ERMs may be used for optimized O\&M planning and autonomous control applications. These applications may require estimates of risk over different time horizons, from the instantaneous risk to the risk during a specific maintenance action or configuration period to the risk until the next scheduled outage.

\subsection{Meet Runtime Requirements for Control and O\&M Planning}

To provide input to supervisory control and/or O\&M planning routines, the ERMs will need to meet the appropriate runtime requirements. The intended use for ERM outputs will define the runtime requirements (e.g., execution speed). These will need to be considered as methods to incorporate ERM results into control and planning applications are developed. 


\subsection{State of the Art}

\subsection{Risk Monitors}

NPPs are required to evaluate the risk of entering any non-standard configuration (such as online maintenance activities) by the U.S. NRC Maintenance Rule (i.e., 10 CFR 50.65 2011). A common approach to fulfilling this requirement is application of risk monitors. Risk monitors incorporate the actual plant configuration into PRA models to provide a point-in-time risk assessment for the current plant configuration and environmental factors (OECD/NEA 2004). They are used online by control room staff that regularly input information to update the current plant configuration and monitor the plant using the quantitative and qualitative risk measures, and they are used offline for planning future maintenance outages, long-term risk profiling, analyzing cumulative risk, and evaluating unplanned events such as equipment failures. PRA models generally have to be adapted for use in a risk monitor; for example, the PRA is modified to ensure that the point-in-time risk is calculated (rather than the average risk) by incorporating seasonal variations in initiating events. One of the primary uses for PRA and risk monitors in operating plants is evaluating core damage frequency for different plant configurations, possibly resulting from online maintenance activities. PRA can be used to determine which equipment could be taken out of service and for how long by looking at the changes in the core damage frequency that result from taking certain equipment out of service. Typical risk measures for maintenance planning include allowed outage time (AOT) and allowed configuration time (ACT). AOT is the maximum time that a non-standard plant configuration can persist before the plant must be moved to a safer (lower-risk) state. The plant technical specifications prescribe bounding plant configurations and maximum AOTs for components and system trains. ACT is a measure that represents the risk increase in the out-of-service configuration. Exceeding certain ACT values may supersede allowed AOT with a shorter allowable time based on the incremental risk for the current plant configuration. A thorough review of the development and status of risk monitors is given in OECD/NEA (2004).

A variety of software packages are available to develop and evaluate risk monitors in NPPs (OECD/NEA 2004); these software packages will not be reviewed here. In general, the available software supports both qualitative and quantitative measures of risk. Previous generations of risk monitors calculate the core damage frequency and large early release frequency (common quantitative risk measures) by (1) solving a simplified PRA model, (2) evaluating a group of predetermined cut-sets, or (3) extrapolating from the pretabulated results of evaluating the PRA for a variety of plant configurations. Newer risk monitors solve the full PRA model each time a point-in-time estimate of risk is needed. This approach gives more accurate assessment of the risk and provides more flexibility in modeling environmental factors; however, the computational burden and execution time of performing a full PRA analysis may preclude frequent online, real-time evaluation.

\subsection{Equipment Condition Assessment}

ECA has been an active area of research for several decades. Several reviews of ECA research and developments are available [e.g., Schwabacher (2005), Schwabacher and Goebel (2007), and Hines et al. (2008)]. Kothamasu et al. (2006) reviews approaches to system health monitoring and prognostics, including specific applications to vibration monitoring of rotating equipment, gearboxes, and bearings. The Electric Power Research Institute (EPRI) extended their existing Preventative Maintenance Basis 
Database to include an assessment of the applicability of prognostics to various systems and components in power generating systems (EPRI 2009); this assessment includes a list of potential measurements for assessing degradation. A recent review by Coble et al. (2012) summarizes the state of the art in equipment monitoring, fault detection, diagnostics, and prognostics for NPP components and systems. ECA systems, including predictive maintenance, prognostics and health management (PHM), and health monitoring, typically detect and diagnose faults and estimate the remaining useful life of a system or component, but this approach can be modified and extended to instead provide the instantaneous probability of failure distribution or the POF over some specified time window.

Active components in NPPs include pumps, valves, motors, bearings, etc. For these active components, PHM systems can capitalize on the information already collected by the plant I\&C system, such as temperature, flow, and pressure. Pump health may be estimated using discharge pressure and flow; valve operation could be monitored through the changes in flow as the valve position setpoint is changed. For some active components, additional measurements may be useful or necessary for more robust and accurate prognostic models. Pumps and motors can be monitored through vibration measurements (e.g., Jarrell et al. 2004); in fact, reactor coolant pumps and casing are commonly monitored through the reactor coolant pump vibration monitoring system (Koo and Kim 2000). However, these systems do not currently support automated, online analysis of the vibration data to detect and diagnose abnormal conditions. Motors, such as those used for motor-operated valves (MOVs), can be monitored through multiple features, including input current and voltage, active power, motor position measures, and applied forces. Many of these additional measurements may be obtained autonomously, online, and unobtrusively.

While aSMRs will likely employ some advanced component designs (e.g., magnetic pumps and bearings), work on conventional component designs forms a basis for developing similar monitoring capabilities for these new designs. Based on the operational experience summarized in Section 2.1, components of particular risk-importance may include pumps, valves, motors, and control rod drive systems. ECA approaches and measurements for these types of components are given in Table 4.1.

Reactor coolant pumps (RCPs) have received significant research attention because of the significant economic losses during extended plant shutdowns for pump maintenance and replacement. Casada (1994) and Greene et al. (1995) review degradation and performance monitoring for centrifugal pumps, including vibration monitoring (both frequency and amplitude), pump head monitoring, flow rate monitoring, dynamic pressure analysis, and motor power analysis. More recent approaches to pump condition assessment have focused on stressor-based analysis and advanced frequency-based vibration analysis.

NPPs commonly employ check valves and MOVs. The NRC has mandated periodic inspection of these valves, which typically involves partial disassembly. Methods to evaluate the condition of valves online have been under development for decades to potentially relieve these offline inspections. Haynes (1990) gives a review of monitoring and diagnostic methods for check valves, focusing on acoustic emission, ultrasonic inspection, and magnetic flux signature analysis. Lewis (1994) suggests two approaches for monitoring MOVs: motor control center testing (e.g., motor current signature analysis, actuator output torque margin, control switch operation) and monitoring valve parameters (e.g., stem force and torque, motor current and power, switch state sensing). 
Table 4.1. Example Equipment Condition Assessment Methods for Selected Active Components in NPPs

\begin{tabular}{|c|c|c|c|}
\hline $\begin{array}{l}\text { Component } \\
\text { Type }\end{array}$ & $\begin{array}{c}\text { Condition Assessment } \\
\text { Approach }\end{array}$ & Measurements & Selected References \\
\hline \multirow{3}{*}{ Pumps } & Process monitoring & $\begin{array}{l}\text { Speed, vibration, power, } \\
\text { discharge pressure }\end{array}$ & (Gross et al. 1993) \\
\hline & $\begin{array}{l}\text { Stressor-based } \\
\text { assessment }\end{array}$ & & (Jarrell et al. 2004) \\
\hline & Frequency analysis & Vibration & $\begin{array}{l}\text { (Koo and Kim 2000; Jung and Seong } \\
\text { 2006; Sharp 2012) }\end{array}$ \\
\hline \multirow{6}{*}{ Valves } & Nondestructive & Acoustic emission & (Nakamura and Terada 1985) \\
\hline & evaluation & Ultrasonic inspection & (McShane and Ulerich 1992) \\
\hline & & $\begin{array}{l}\text { Motor current and valve stem } \\
\text { strain and position }\end{array}$ & (Arcella et al. 1994) \\
\hline & & Position & (Daigle and Goebel 2010) \\
\hline & Electrical analysis & Voltage and current & (Granjon 2011) \\
\hline & & Stator variables & (Chai et al. 1994) \\
\hline \multirow{4}{*}{ Motors } & Vibration monitoring & Vibration & $\begin{array}{l}\text { (Seker et al. 2003; Maruthi and Vittal } \\
\text { 2005; Korkua et al. 2010) }\end{array}$ \\
\hline & $\begin{array}{l}\text { Motor current signature } \\
\text { analysis }\end{array}$ & Motor current & $\begin{array}{l}\text { (Thomson and Fenger 2001; Seker et } \\
\text { al. 2003; Eren et al. 2005) }\end{array}$ \\
\hline & & Current, voltage, motor speed & (Trutt et al. 2002) \\
\hline & Digital rotor telemetry & & (Maughan and Reschovsky 2010) \\
\hline \multirow{4}{*}{$\begin{array}{l}\text { Control Rod } \\
\text { Drive }\end{array}$} & & $\begin{array}{l}\text { Current signal and noise } \\
\text { analysis }\end{array}$ & (Gunther and Sullivan 1991b) \\
\hline & & $\begin{array}{l}\text { Circuit continuity and } \\
\text { insulation integrity in coils }\end{array}$ & (Gunther and Sullivan 1991b) \\
\hline & & Neutron noise analysis & (Pázsit and G Th Analytis 1980) \\
\hline & & Control rod position & (Wallace et al. 2010) \\
\hline \multirow{3}{*}{$\begin{array}{l}\text { Turbine- } \\
\text { Generator }\end{array}$} & Process monitoring & $\begin{array}{l}\text { Steam pressure, condenser } \\
\text { pressure, valve position, } \\
\text { turbine and generator speed }\end{array}$ & (Ayaz 2008) \\
\hline & Oil analysis & $\begin{array}{l}\text { Particle counting, wear debris } \\
\text { monitoring, elemental } \\
\text { composition of wear debris }\end{array}$ & $\begin{array}{l}\text { (Ahn et al. 1996; Prabhakaran and } \\
\text { Jagga 1999) }\end{array}$ \\
\hline & Vibration monitoring & Vibration & (Yan and Goebel 2003) \\
\hline
\end{tabular}

Several online, nondestructive approaches have been developed for monitoring motor health, including vibration analysis, motor current signature analysis, thermography, and operational monitoring (Hudson 1999). More recently, digital rotor telemetry suites have been developed to directly measure voltage, current, insulation resistance to ground, average winding temperature, and winding hot spot temperature during operation (Maughan and Reschovsky 2010).

The control rod drive system consists of both the control rods and the mechanical and electrical systems that control the motion and position of the control rods (e.g., control rod drive mechanism, power and logic cabinets, cables, connectors, and rod position indication system); these systems and components are located both inside and outside containment. The U.S. NRC's Nuclear Plant Aging Research (NPAR) 
program found several components with common aging problems that could contribute to control rod functional failure, including cables, coils, rod position indication system, fuses, and power electronics (Gunther and Sullivan 1991a, b).

\subsubsection{Estimating Failure Probabilities}

Development of component failure data, such as that used to estimate failure probabilities for PRA, typically involves characterization of the expected lifetime of an average system or component operating in an average environment, under average usage conditions. Distributions of component failure probability can be derived through various reliability analyses that use measured component or system lifetimes (under expected or accelerated conditions) to evaluate a distribution of expected lifetimes (Abernethy 2004). A readily apparent shortcoming of this population-based component failure data is the absence of consideration for unit-specific factors - unit-to-unit variability, maintenance and service activities, and experienced loads and stresses. Degradation analysis has been used to augment reliability analysis and component lifetime data to compensate for the small number of failures seen during accelerated aging tests as equipment becomes more reliable (Lu and Meeker 1993). In fact, Lu et al. (1996) found that degradation-based reliability prediction provides more precision than traditional time-to-failure analysis, even in the face of measurement error. These early efforts to incorporate degradation data in reliability were focused on improving estimations of population statistics. Chinnam $(1999,2002)$ extended degradationbased reliability analysis to individual components. This work focused on estimating the reliability function given only measurements to the current time. Xu and Zhao (2005) describe an approach to predict the reliability of a specific component based on predicted degradation measures and expected stressors (which may or may not be stochastic) at some future point in time. This approach can be expanded by including ECA at the front end to related available measurements to component degradation measures (Figure 4.1). Prognostic algorithms can be used to extrapolate these degradation measures to a time of interest, $t_{i}$, in the face of stressors. Table 4.2 summarizes some prognostic algorithms that may be applied to active components. Xu and Zhao suggest two approaches to estimating the POF given the predicted degradation measures: a logistic function (for the case where stressors are precisely known) and a probability assessment (considering random stress conditions).
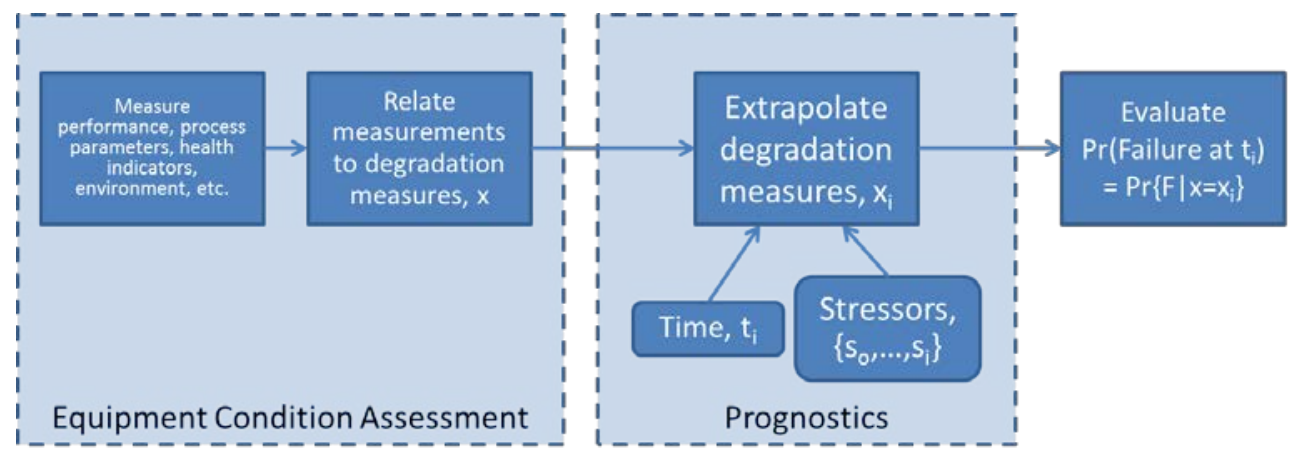

Figure 4.1. Equipment Condition Assessment Routines and Prognostic Models can be used to Evaluate the POF at Time $t_{i}$ Given the Expected Stresses 
The predicted POF should actually be a probability density function itself. Sources of uncertainty at nearly every step in the above evaluation approach will result in uncertainty in the predicted POF:

measurement uncertainty, inaccuracy in the models that relate measurements to degradation, uncertainty in future stress conditions, inaccuracy in prognostic models to extrapolate degradation measures, and uncertainty in the POF evaluation method. The POF distribution needs to be understood and quantified to support evaluation of the uncertainty in the results of the enhanced risk monitor. 
Table 4.2. Selected Prognostic Algorithms for Active Components

\begin{tabular}{|c|c|c|c|c|c|c|}
\hline \multirow[b]{2}{*}{ Algorithm } & \multirow[b]{2}{*}{ Assumptions and Comments } & \multicolumn{4}{|c|}{ Pros and Cons } & \multirow[b]{2}{*}{$\begin{array}{c}\text { Selected } \\
\text { References }\end{array}$} \\
\hline & & $\begin{array}{l}\text { Data vs } \\
\text { Physics }\end{array}$ & $\begin{array}{l}\text { Prediction } \\
\text { Time }\end{array}$ & $\begin{array}{l}\text { Inherent } \\
\text { Uncertainty } \\
\text { Estimates }\end{array}$ & $\begin{array}{l}\text { Handles } \\
\text { Nonlinear } \\
\text { Degradation } \\
\text { Growth }\end{array}$ & \\
\hline $\begin{array}{l}\text { Traditional } \\
\text { Reliability } \\
\text { Analysis }\end{array}$ & $\begin{array}{l}\text { Estimates the average lifetime of a population of } \\
\text { similar components with similar service. This } \\
\text { method is currently used in PRA and risk } \\
\text { monitors to estimate failure probabilities }\end{array}$ & lifetime data & very short & $\checkmark$ & & $\begin{array}{l}\text { (Girish et al. } \\
\text { 2003; Chen and } \\
\text { Zheng 2005) }\end{array}$ \\
\hline $\begin{array}{l}\text { Proportional } \\
\text { Hazards } \\
\text { Models }\end{array}$ & $\begin{array}{l}\text { Uses operation condition-based covariates to } \\
\text { modify a baseline hazard function }\end{array}$ & lifetime data & very short & $\checkmark$ & & (Dale 1985) \\
\hline $\begin{array}{l}\text { Physics of } \\
\text { Failure Models }\end{array}$ & $\begin{array}{l}\text { Requires well-developed models of fault-to- } \\
\text { failure progression. Often, significant } \\
\text { simplifying assumptions must be made to } \\
\text { support model development and execution }\end{array}$ & $\begin{array}{l}\text { well-defined } \\
\text { physics of } \\
\text { failure models }\end{array}$ & usually long & & $\checkmark$ & \\
\hline $\begin{array}{l}\text { Life } \\
\text { Consumption } \\
\text { Models }\end{array}$ & $\begin{array}{l}\text { Operation at a given condition consumes some } \\
\text { set amount of life, which is subtracted from the } \\
\text { expected equipment life. }\end{array}$ & $\begin{array}{l}\text { uses physics of } \\
\text { failure models } \\
\text { to estimate life } \\
\text { consumed }\end{array}$ & $\begin{array}{l}\text { could be long, } \\
\text { depending on } \\
\text { consumption } \\
\text { model }\end{array}$ & & & $\begin{array}{l}\text { (Ramakrishnan } \\
\text { and Pecht 2003) }\end{array}$ \\
\hline $\begin{array}{l}\text { Markov Chain } \\
\text { Models }\end{array}$ & $\begin{array}{l}\text { Future operating conditions are stochastic and do } \\
\text { not depend on the history of operation. Transi- } \\
\text { tion probabilities may be dynamic, dependent on } \\
\text { time, condition, operating history, etc. Operation } \\
\text { at a given condition results in a set amount of } \\
\text { degradation. }\end{array}$ & either & $\begin{array}{l}\text { may be long, } \\
\text { depending on } \\
\text { number of } \\
\text { simulations }\end{array}$ & $\checkmark$ & & (Hines et al. 2008) \\
\hline Shock Models & $\begin{array}{l}\text { Continuous in both time and degradation, } \\
\text { assumes shocks of random magnitude arrive at } \\
\text { random times. Distributions are dependent on } \\
\text { operating conditions, time, or current condition. }\end{array}$ & either & $\begin{array}{l}\text { may be long, } \\
\text { depending on } \\
\text { number of } \\
\text { simulations }\end{array}$ & $\checkmark$ & & (Hines et al. 2008) \\
\hline $\begin{array}{l}\text { General Path } \\
\text { Model }\end{array}$ & $\begin{array}{l}\text { A parametric model (regression, neural network, } \\
\text { etc.) is fitted to a prognostic parameter and } \\
\text { extrapolated to the failure threshold }\end{array}$ & data & usually fast & & $\checkmark$ & $\begin{array}{l}\text { (Upadhyaya et al. } \\
\text { 1994; Coble 2010) }\end{array}$ \\
\hline $\begin{array}{l}\text { LEAP-Frog } \\
\text { Model }\end{array}$ & $\begin{array}{l}\text { Linear degradation extrapolation with a short } \\
\text { window of data used for fitting to give faster } \\
\text { response to system changes }\end{array}$ & neither & usually fast & & $\begin{array}{l}\text { no--uses linear } \\
\text { extrapolation }\end{array}$ & $\begin{array}{l}\text { (Greitzer and } \\
\text { Ferryman 2001) }\end{array}$ \\
\hline
\end{tabular}


Table 4.2. (continued)

\begin{tabular}{|c|c|c|c|c|c|c|}
\hline \multirow[b]{2}{*}{ Algorithm } & \multirow[b]{2}{*}{ Assumptions and Comments } & \multicolumn{4}{|c|}{ Pros and Cons } & \multirow[b]{2}{*}{$\begin{array}{c}\text { Selected } \\
\text { References }\end{array}$} \\
\hline & & $\begin{array}{l}\text { Data vs } \\
\text { Physics }\end{array}$ & $\begin{array}{l}\text { Prediction } \\
\text { Time }\end{array}$ & $\begin{array}{c}\text { Inherent } \\
\text { Uncertainty } \\
\text { Estimates }\end{array}$ & $\begin{array}{c}\text { Handles } \\
\text { Nonlinear } \\
\text { Degradation } \\
\text { Growth }\end{array}$ & \\
\hline $\begin{array}{l}\text { Particle } \\
\text { Filter }\end{array}$ & $\begin{array}{l}\text { Applied when the process model is non-linear and/or } \\
\text { the noise terms are non-Gaussian }\end{array}$ & either & $\begin{array}{l}\text { may be long, } \\
\text { depending on } \\
\text { number of } \\
\text { particles }\end{array}$ & $\checkmark$ & $\checkmark$ & $\begin{array}{l}\text { (Daigle and } \\
\text { Goebel 2010; } \\
\text { Saha and Goebel } \\
\text { 2011) }\end{array}$ \\
\hline $\begin{array}{l}\text { Extended } \\
\text { Kalman } \\
\text { Filter }\end{array}$ & Applies to nonlinear Gaussian systems. & either & $\begin{array}{l}\text { may be long, } \\
\text { depending on } \\
\text { number of } \\
\text { simulations }\end{array}$ & $\checkmark$ & $\begin{array}{l}\text { Handles some } \\
\text { non-linearity }\end{array}$ & \\
\hline
\end{tabular}





\subsection{Gaps and Technical Needs}

A comparison of requirements identified and the current state-of-practice highlights the technical gaps associated with the development and deployment of ERMs for aSMRs. The identified technical gaps are:

- Equipment condition assessment for advanced components and systems: No risk monitor or PRA framework was found that incorporates or proposes to incorporate an estimate of the POF of specific active SSCs in a specific plant. Equipment condition assessment can compensate for the lack of reliability data for aSMR systems and components. Significant work has been done in development of ECA and prognostics for conventional SSCs, in both nuclear and non-nuclear applications. The developed condition indicators and models need to be evaluated for application to aSMR components and environments to assess their efficacy. If the existing models are not sufficient, new approaches to equipment condition assessment may be needed (e.g., for advanced component designs or convention components operating in new regimes). Related questions that need to be addressed include:

- Incorporating uncertain future conditions including changing operational conditions and "normal" load transients.

- Estimating component reliability given the unavailability of connected components.

- Identifying high-value components that provide the greatest benefit to plant goals when outfitted with ECA.

- Accident scenarios for aSMRs: Severe accident scenarios and the associated event and fault trees are well developed for LWRs, but scenarios in aSMRs may include a fundamentally different set of initiating events due to the differences in design and operation. Even for common initiating events, the sequence of events leading to undesired consequences may differ significantly for aSMRs.

- Interconnected modules with potential load mismatch: Existing dynamic and living PRA frameworks focus on conventional single-module reactors. The implications of including multiple modules in a single plant, including potential system dependencies and the effect of physical proximity during external events such as earthquakes, fire, or flooding will need to be investigated. Additionally, ERMs need to account for the possibility of common cause failures for components across modules.

- PRA models that account for load variation, cogeneration, and reconfigurable BOP: Accident sequences, fault trees, and/or success criteria may change as the operating load rises and falls. aSMR modules are expected to exhibit dynamic loads as a result of load-following, balancing output across modules, and balancing power production with other missions. The possible effects of varying loads on the risk assessment need to be better understood and quantified.

- Risk measures for aSMR safety, economics, and demand: New measures of risk may be needed to accurately quantify the risks for aSMRs. In addition to traditional measures of risk, economic risks may also be of interest, such as the probability (risk) of plant or module downtime. An accurate view of the potential effects of different plant/module configurations on the ability to continue generating power/heat will support longer operating cycles between outages and improve the ability to meet power generation demands across the entire plant. 
- Risk evaluation at multiple time horizons: Different time horizons for risk measures may be required by different applications (e.g., risk over the duration of a maintenance action, total risk until next outage under specified operating conditions, instantaneous risk). ERMs must be flexible enough to evaluate risk over any or all required time horizons, depending on the ultimate use of the results.

- Runtime requirements: The ERM is envisioned as a tool to use in real-time or near-real-time to support operations and maintenance planning and autonomous control. As algorithms for these applications are developed, ERM will need to be evaluated to meet the runtime requirements that they impose. 


\subsection{Preliminary Research Plan}

This section outlines a preliminary research plan to develop an ERM framework for aSMRs. The proposed research will develop a process for incorporating equipment condition assessment and prognostic results into risk monitors to provide greater situational awareness in the face of new concepts of operation, such as load following, multi-modularity, and dual-mission generation. The objective of this research is given in Subsection 6.1. Several assumptions have been made in developing this research plan, which are summarized in the following subsection. Then, the major tasks to development of an ERM framework are described with a proposed timeline for completion. Potential simulations and experiments to develop, test, and demonstrate the ERM framework are also described.

\subsection{Research Objective}

This research will support the safety and economic goals for aSMRs by providing a dynamic assessment of system risk. Enhanced risk assessment of critical active components will improve asset protection and management, allowing for safe, reliable generation during extending operating cycles and longer reactor lifetimes. Incorporation of dynamic health assessment of key active components in risk monitors will also support the economics and minimize the long-term costs of aSMRs by (1) informing O\&M decisions to target maintenance activities during outages, (2) optimizing plant performance, and (3) supporting extended operating cycles by ensuring reliable component operation. This heightened risk awareness is particularly important for aSMRs because of their compact design and modular operation, location of key components internal to the vessel, and extended periods between maintenance opportunities.

The major considerations for developing an enhanced risk monitor for a specific system or plant are shown in Figure 6.1. These steps can be roughly related to components, measurements, ECA, prognostics, and, finally, ERM development. The first step in developing an ERM is to identify the risksignificant SSCs, that is, the components and systems that contribute most to the overall risk. A welldeveloped PRA model can be used to identify and rank the contributors to overall risk. These key SSCs are then candidates for health monitoring and ECA. The second step is to identify measurements that can provide indicators of condition for each of the key SSCs. These measurements may include process measurements (e.g., flow, temperature, pressure), performance measurements (e.g., pump efficiency), or direct measurements (e.g., vibration, acoustic emissions). These measurements are combined with analysis algorithms in the third step: equipment condition assessment. ECA maps the available measurements to condition indicators. The condition indicator can then be projected to future times using appropriate prognostic algorithms (step 4). As described in Section 4.2.1, the prognostic model results can be used to estimate the POF distributions for each key SSC at some point in the future. Finally, the estimated POF distributions are inputted to the ERM to provide a more accurate assessment of the realtime risk. The ERM model can be used to evaluate multiple risk measures (e.g., measures related to safety, economics, or availability) over multiple time horizons (e.g., while an elevated load is expected to persist, during a maintenance action, or over the remainder of a fuel cycle). The estimated risk must be accompanied by a measure of the uncertainty associated with that risk, in order to be useful for supervisory control and O\&M planning and optimization routines. The research outlined here will address some of the open questions summarized in Section 5.0 and will provide the framework for deploying an ERM for a specific aSMR design. 


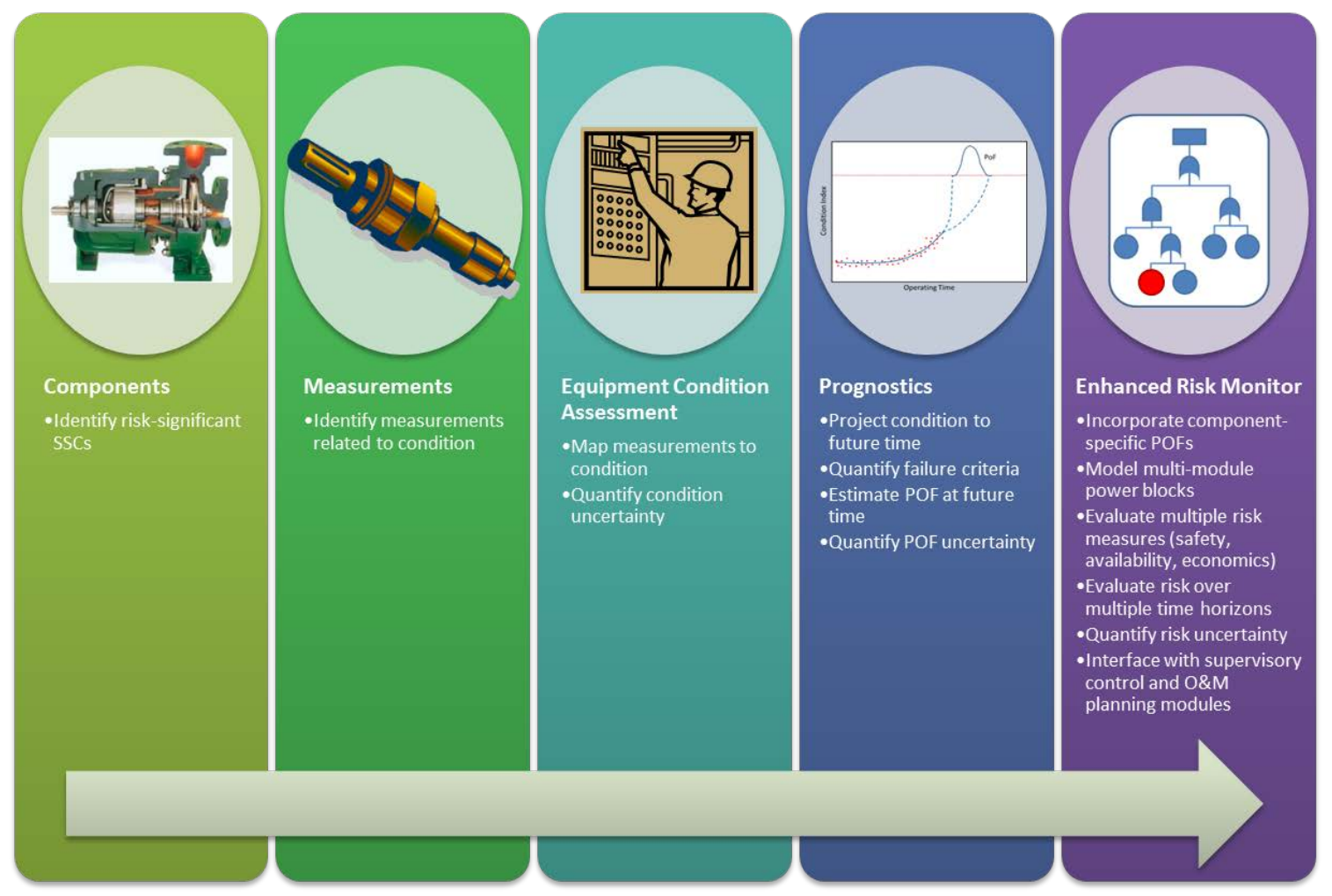

Figure 6.1. Considerations and Steps to Achieving an Enhanced Risk Monitor

\subsection{Key Assumptions}

Several key assumptions are made to maintain the focus of this work on incorporating equipment condition assessment in real-time risk monitors.

Effective ECA techniques are assumed to be available for key active components and systems, including identification of the measurements necessary to perform ECA. This project may develop simple ECA techniques as necessary, but development of accurate condition assessment methods will not be the primary focus of this work. Furthermore, we assume that existing prognostic algorithms will provide accurate extrapolation of equipment condition through future operation; new approaches to prognosis are not a focus of this research.

This research plan also assumes that cross-coupling of components and systems in connected reactor modules will be captured in well-developed PRA models. The initial ERM methodology will not explicitly account for these interdependencies. However, as the research progresses, this assumption will be tested and relaxed, if necessary.

A prototypical aSMR design and configuration will be used to test and demonstrate the ERM framework. A pool-type liquid metal reactor will be assumed for the reactor modules. This reactor type offers several advantages, chief of which is the expertise available in the research team and elsewhere in the National Laboratory complex in the area of sodium-cooled fast reactors. Additionally, early efforts to develop PRA models for pool-type liquid metal reactors (e.g., EBR II) are available to guide risk models 
used in this work. A generic design with multiple aSMR reactor modules connected to a common BOP, which can include both electricity generation and process heat applications, will be assumed. This will be referred to as a generation block (Figure 6.2). A single prototypical aSMR plant contains multiple generation blocks.

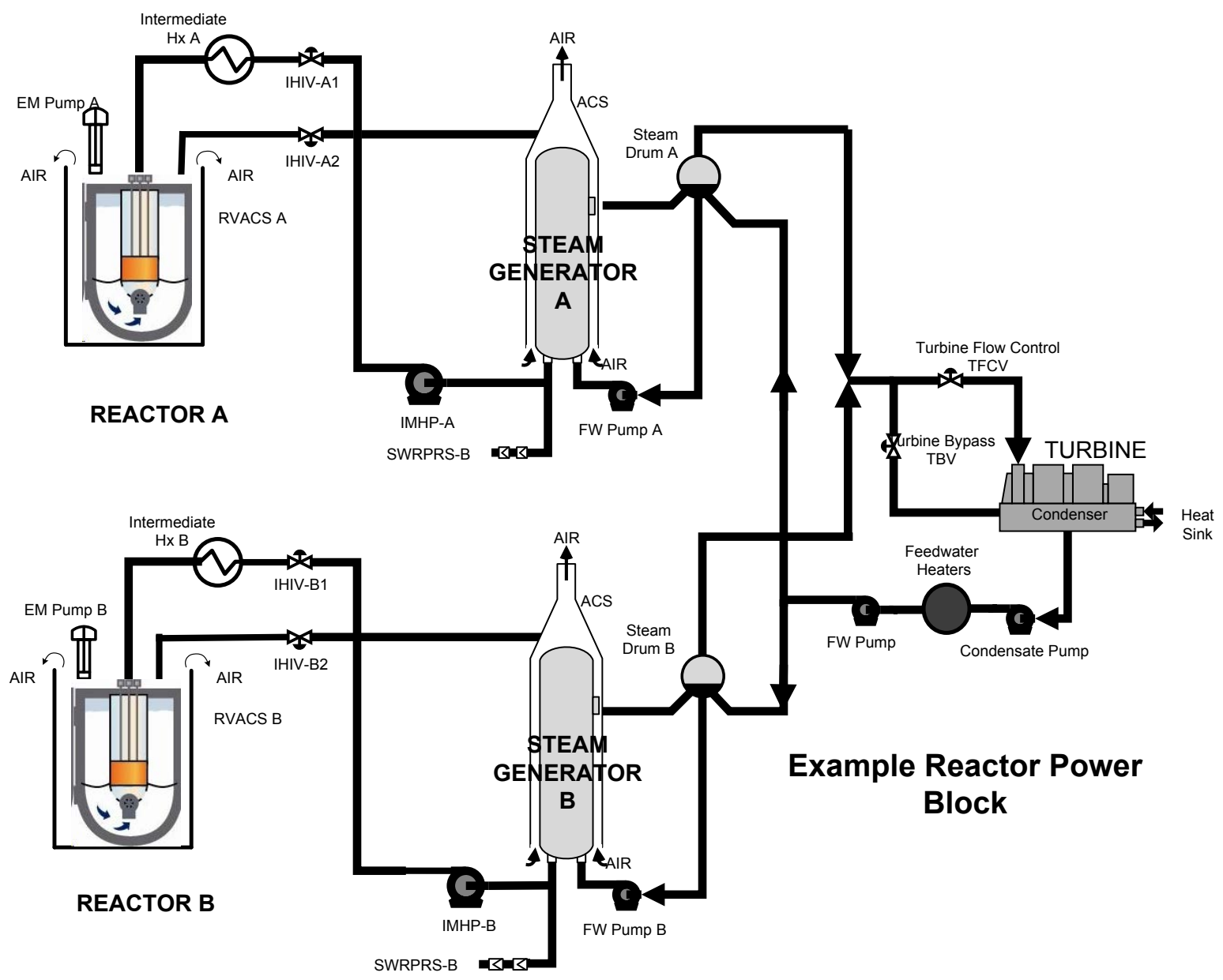

Figure 6.2. A Single Generation Block in the Proposed aSMR Plant Configuration. A full plant would be comprised of multiple generation blocks.

\subsection{Development of Conceptual ERM Framework}

Key active components will be identified as those considered "risk significant," meaning that failure of a key component contributes a significant amount of the overall risk. "Significant" will be quantified as appropriate risk measures are identified. Risk measures may be defined non-traditionally as typically measures such as CDF and LERF are expected to be one or two (or more) orders of magnitude less than for currently operating reactors. As described above, existing developments in the areas of degradation measurement, equipment condition assessment, and prognostics will be leveraged, with the focus of research on methods to incorporate the condition indices and POF into operational risk monitors and on a 
framework for ERM. Exploration of different ways that condition indices and POFs should be incorporated into a risk monitor will be performed. Current risk monitors vary system configuration and sometimes event or failure likelihoods, but do not change success criteria or the underlying fault tree and event structures in the PRA. Also, as explained ahead, differentiation of kind risk and more explicit consideration of uncertainty may be desired. Consideration of these complexities may require new thinking about the PRA modeling supporting ERM.

\subsubsection{Identify Appropriate Risk Measures for aSMRs}

Because of new passive safety features, typical risk measures, such as CDF, are expected to be orders of magnitude lower for most aSMRs than for currently operating reactors. For example, the latest publically available PRA results for PRISM present accident sequence CDFs in the range of $10^{-8}$ to $10^{-12}$ for a total CDF on the order of $10^{-8}$ (NRC 1994). For some aSMR designs, CDF may not be a meaningful measure of risk, because enhanced fuels will preclude any significant fuel failure. However, new, nontraditional risk measures could be identified that support the economic and production goals of aSMRs, in addition to safety goals. Appropriate risk measures, such as availability or capacity, need to be selected to support supervisory control and O\&M planning. Along with identifying appropriate risk measures, criteria need to be established to assess the acceptability of plant configurations based on risk results (Puglia and Atefi 1995). The risk acceptance criteria can be used to assess the amount of time that the plant can remain in a specific configuration, potentially replacing the deterministic AOT with a dynamic risk-based assessment supported by equipment condition assessment. Establishing acceptance criteria for different risk measures is an operational issue that will be considered in conjunction with the development of supervisory control and O\&M planning algorithms, although site-specific acceptance criteria will likely need to be developed by utilities and regulators.

\subsubsection{Incorporate Unit-Specific POF}

Using accurate, real-time estimates of component failure probabilities is the primary enhancement proposed for the ERM. Although the concept is straightforward, execution will require the integration of measurements, condition assessment, and prognosis. The results of this analysis may be used to estimate the actual POF of a specific unit at a given point in time or over a specified period of time. This research will develop a framework to move from measurements through condition assessment and individual POF assessment to enhanced risk monitors.

\subsubsection{Evaluate Overall Uncertainty}

Current PRA and risk monitors evaluate risk uncertainty that results from uncertainty in the component POF, as described in Section 2.4. Uncertainty from several sources (measurement noise, model error, unknown future loads, etc.) will contribute to the uncertainty in the unit-specific POF. Additionally, uncertainty in future operating conditions and loads may introduce additional uncertainty in the PRA models used to evaluate the risk. The introduction of additional uncertainty may need to be explicitly addressed by the ERM. Current risk monitors provide information based on point-values or calculated mean values. New risk measures may need to be identified that incorporate quantitative estimation of composite uncertainty. Exceeding an uncertainty threshold may need to be considered in decision making. The existing approach to estimating risk uncertainty will need to be evaluated to 
determine if it is sufficient for ERM. If this approach does not provide accurate estimates of overall risk uncertainty given the potential uncertainty sources, new methods will be developed.

\subsubsection{Incorporate Dynamic Success Criteria}

As operating conditions and load demands on individual reactors and generation blocks change, the appropriate success criteria may also change. For instance, a reactor module operating at $90 \%$ capacity may require reactor coolant flow at $100 \%$, while a module operating at only $40 \%$ capacity may be adequately served by the reduced flow and heat transfer or heat transfer from secondary heat removal source. Current risk monitors do not consider the effect of changing loads and operating conditions on success criteria.

\subsubsection{Incorporate ERM Results in Supervisory Control and O\&M Planning}

The results of online ERM analysis can provide information to support supervisory control and optimized O\&M planning. As the ERM is developed, the requirements of supervisory control will be considered (e.g., risk measures, time horizons for risk assessment, and runtime requirements). In turn, the ERM will push requirements to the supervisory control algorithm development, such as information about the projected future reactor module and generation block operation.

\subsubsection{Simulations and Experiments}

A series of simulations and experiments will be used in the development, testing, and demonstration of the ERM framework. The simulations are expected to be coordinated with the aSMR simulation project (also being conducted under the ICHMI technical area), with data from the simulations being used for testing and verification of the ERM framework. In addition, smaller-scale simulations of individual components will also be performed to enable testing of individual elements of the ERM framework such as equipment condition assessment. The simulations will be augmented with bench-scale experiments and publicly available data sets of equipment condition assessment. Initial testing will be conducted around the simplified PRA model, with additional testing as the complexity of the framework is increased. A test loop will be used to demonstrate the ERM framework. This loop will include key active components with well-defined ECA models to provide accurate condition information.

\subsubsection{Research Activities}

An initial research plan is outlined here for the remainder of the project, with a notional timeline given in Figure 6.3. The tasks for Phase 2 and 3 will be defined as work progresses.

\begin{tabular}{|c|c|c|c|c|c|c|c|c|c|c|c|c|}
\hline \multirow[t]{2}{*}{ Task Name } & \multicolumn{4}{|l|}{ Year 1} & \multicolumn{4}{|l|}{ Year 2} & \multicolumn{4}{|l|}{ Year 3} \\
\hline & Qtr 1 & Qtr 2 & Qtr 3 & Qtr 4 & Qtr 1 & Qtr 2 & Qtr 3 & Qtr 4 & Qtr 1 & Qtr 2 & Qtr 3 & Qtr 4 \\
\hline \multicolumn{13}{|l|}{ Phase 1} \\
\hline \multicolumn{13}{|l|}{ Prototypic PRA } \\
\hline \multicolumn{13}{|l|}{ Dynamic POF Incorporation } \\
\hline \multicolumn{13}{|l|}{ Uncertainty Quantification } \\
\hline \multicolumn{13}{|l|}{ Phase 2} \\
\hline \multicolumn{13}{|l|}{ Phase 3} \\
\hline
\end{tabular}

Figure 6.3. Notional Timeline for Research Activities 


\subsubsection{Phase 1: Framework for Incorporating Dynamic POF Values in PRA}

Work during the remainder of Phase 1 will focus on developing the framework for incorporating updated POF values into PRA models to give a dynamic assessment of risk.

- Prototypic PRA: Develop a simple PRA model for prototypical aSMR design. PRA model development will include identification of appropriate risk measures, such as productivity or availability; these risk measures will be identified in collaboration with the supervisory control project. This simple model will consist of a set of cutsets defining the major accident contributors. As the research progresses, the model complexity will be increased, by defining a series of event trees and associated fault trees for key initiating events.

- Dynamic POF Incorporation: Assess methods to incorporate dynamic POF measures in risk monitors. Using the simplified PRA model, the effect of incorporating changing POF values will be investigated with simulated equipment condition information. As methods are developed to incorporate simulated unit-specific POF values, ECA and prognostic models will be implemented with simulated equipment measurements to provide more realistic results. This will be a major focus of FY13.

- Uncertainty Quantification: Quantify overall risk estimate uncertainty. The uncertainty in risk estimates must account for uncertainty in the equipment condition assessment, the prognostic result, and the PRA model. Existing approaches to evaluate uncertainty in PRA results will be investigated to determine the suitability of applying these methods to the ERM. If these methods are not sufficient, new approaches to uncertainty assessment will be explored.

\subsubsection{Phase 2}

Work during Phase 2 will investigate methods to change the success criteria under changing operating conditions. The importance of this capability will be evaluated to determine if it is necessary for accurate estimates of plant risk. Additional complexity will be included in the prototypic PRA model to incorporate multiple generation blocks at a single site. An initial assessment of ERM will be made using simulated data for selected active components.

\subsubsection{Phase 3}

Work during Phase 3 will demonstrate the ERM on representative models or test beds of a selected aSMR subsystem. 


\subsection{Summary}

The ability to incorporate unit-specific estimates of the POF of specific active components in aSMRs, by utilizing real-time or near-real-time condition knowledge of the equipment, into operational risk monitors has the potential to enable real-time decisions about stress relief for susceptible equipment while supporting effective maintenance planning. Such ERMs, especially as part of a dynamic PRA evaluation that incorporates real-time estimates of the health of active SSCs, are expected to improve the safety and availability of aSMRs.

The particular eccentricities of advanced reactors and small modular reactors provide unique challenges and needs for advanced ICHMI techniques such as ERMs in aSMRs. Several features of aSMR designs increase the need for accurate characterization of the real-time risk during operation and maintenance activities. A number of technical gaps in realizing ERMs exist, and these gaps are largely independent of the specific reactor technology. As a result, the development of a framework for ERMs would enable application of the technology regardless of the specific class of reactor technology. A set of research tasks is identified within a preliminary research plan to enable the development, testing, and demonstration of such a framework. Although some aspects of aSMRs, such as specific operational characteristics of aSMRs, are somewhat unclear, the proposed framework is expected to be relevant regardless of such uncertainty. Consequently, the development of ERMs would comprise one of the key technical developments necessary to improve the economic viability of aSMRs. 



\subsection{References}

10 CFR 50.65. 2011. "Requirements for Monitoring the Effectiveness of Maintenance at Nuclear Power Plants." Code of Federal Regulations, U.S. Nuclear Regulatory Commission, Washington, D.C. Available at http://www.nrc.gov/reading-rm/doc-collections/cfr/part050/part050-0065.html.

Abernethy RB. 2004. The New Weibull Handbook. Robert B. Abernethy, North Palm Beach, Florida.

Abram T and S Ion. 2008. "Generation-IV Nuclear Power: A Review of the State of the Science." Energy Policy 36(12):4323-4330.

Adamovich L, S Banerjee, M Bolshunkhin, E Budylov, M Chaki, IV Dulera, P Fomichnko, K Furukawa, B Gabaraev and E Greenspan. 2007. Status of Small Reactor Designs without On-Site Refueling. IAEATECDOC-1536, International Atomic Energy Agency, Vienna, Austria.

Ahn HS, ES Yoon, DG Sohn, OK Kwon, KS Shin and CH Nam. 1996. "Practical Contaminant Analysis of Lubricating Oil in a Steam Turbine-Generator." Tribology International 29(2):161-168.

Apostolakis G. 2000. "The Nuclear News Interview-Apostolakis: On PRA." Nuclear News 43(3):2731.

Arcella FG, FH Bednar, JJ Schreurs and JM Forker. 1994. "Online Valve Diagnostic Monitoring System." Patent Number 5,329,465.

Arjas E and J Holmberg. 1995. "Marked Point Process Framework for Living Probabilistic Safety Assessment and Risk Follow-up." Reliability Engineering \& System Safety 49(1):59-73.

Ayaz E. 2008. "Component-Wide and Plant-Wide Monitoring by Neural Networks for Borssele Nuclear Power Plant." Energy Conversion and Management 49:3721-3728.

Baumhardt RJ and RA Bechtold. 1987. "Five Years Operating Experience at the Fast Flux Test Facility." In ANS/ENS International Conference on Fast Breeder Reactor Systems: Experience Gained and Path to Power Generation. September 13, 1987, Richland, Washington. HEDL-SA-3702; CONF870917-10.

Beck JM, CB Garcia and LF Pincock. 2010. High Temperature Gas-Cooled Reactors Lessons Learned Applicable to the Next Generation Nuclear Plant. INL/EXT-10-19329, Idaho National Laboratory, Idaho Falls, Idaho.

Casada D. 1994. "Detection of Pump Degradation." In 22nd Water Reactor Safety Information Meeting. October 24-26, 1994, Bethesda, Maryland. CONF-9410216--5.

Chai J, RH Lyon and JH Lang. 1994. "Non-invasive Diagnostics of Motor-operated Valves." In Proceedings of 1994 American Control Conference (ACC '94), pp. 2006-2012. June 29-July 1, 1994, Baltimore, Maryland. IEEE, Piscataway, New Jersey.

Chen Z and S Zheng. 2005. "Lifetime Distribution Based Degradation Analysis." IEEE Transactions on Reliability 54(1):3-10.

Chinnam RB. 1999. "On-line Reliability Estimation of Individual Components, Using Degradation Signals." IEEE Transactions on Reliability 48(4):403-412. 
Chinnam RB. 2002. "On-line Reliability Estimation for Individual Components Using Statistical Degradation Signal Models." Quality and Reliability Engineering International 18(1):53-73.

Coble JB. 2010. Merging Data Sources to Predict Remaining Useful Life - An Automated Method to Identify Prognostic Parameters. Ph.D. Thesis, University of Tennessee, Knoxville, Tennessee. Available at http://trace.tennessee.edu/utk_graddiss/683.

Coble JB, P Ramuhalli, LJ Bond, JW Hines and BR Upadhyaya. 2012. Prognostics and Health Management in Nuclear Power Plants: A Review of Technologies and Applications. PNNL-21515, Pacific Northwest National Laboratory, Richland, Washington.

Daigle M and K Goebel. 2010. "Model-Based Prognostics Under Limited Sensing." In 2010 IEEE Aerospace Conference, pp. 1-12. March 6-13, 2010, Big Sky, Montana. DOI 10.1109/AERO.2010.5446822. IEEE, Piscataway, New Jersey.

Dale CJ. 1985. "Application of the Proportional Hazards Model in the Reliability Field." Reliability Engineering 10(1):1-14.

Duffey R and I Pioro. 2005. "Supercritical Water-Cooled Nuclear Reactors: Review and Status." In Nuclear Materials and Reactors - Vol. II from Encyclopedia of Life Support Systems (EOLSS). Eolss Publishers, Oxford, United Kingdom. Developed under the Auspices of the UNESCO. www.eolss.net.

EPRI. 2009. Program on Technology Innovation: Prognostic Application for the Power Industry. Report 1018245, Electric Power Research Institute, Inc. (EPRI), Palo Alto, California.

Eren L, B Onur and MJ Devaney. 2005. IMTC'05, Proceedings of the IEEE Instrumentation and Measurement Technology Conference, 2, pp. 834-837. May 16-19, 2005, Ottawa, Ontario, Canada. IEEE, Piscataway, New Jersey.

Fulwood RR and RE Hall. 1988. Probabilistic Risk Assessment in the Nuclear Power Industry: Fundamentals and Applications. Pergamon Press. ISBN 0080363628.

Girish T, SW Lam and SR Jayaram. 2003. "Reliability Prediction Using Degradation Data - A Preliminary Study Using Neural Network-Based Approach." In European Safety \& Reliability International Conference (ESREL 2003), pp. 681-688. June 15-18, 2003, Maastricht, Netherlands.

Granjon P. 2011. "Condition Monitoring of Motor-Operated Valves in Nuclear Power Plants." In 8th International Conference on Condition Monitoring and Machinery Failure Prevention Technologies (CM/MFPT 2011), pp. 109-119. June 20-22, 2011, Cardiff, Wales. Curran Assoc., Red Hook, New York.

Greene RH, DA Casada, CW Ayers and CC Southmayd. 1995. Detection of Pump Degradation. NUREG/CR-6089, ORNL-6765, U.S. Nuclear Regulatory Commission, Washington, D.C.

Greitzer FL and T Ferryman. 2001. "Predicting Remaining Life of Mechanical Systems." In ASNE Intelligent Ship Symposium IV. April 2-3, 2001, Philadelphia, Pennsylvania. American Society of Navel Engineers (ASNE), Alexandria, Virginia.

Gross KC, RM Singer and KE Humenik. 1993. "Expert System for Online Surveillance of Nuclear Reactor Coolant Pumps." Patent Number 5,223,207. 
Guidez J, L Martin, SC Chetal, P Chellapandi and B Raj. 2008. "Lessons Learned from Sodium Cooled Fast Reactor Operation and Their Ramifications for Future Reactors with Respect to Enhanced Safety and Reliability." Nuclear Technology 164(2):207-220.

Gunther W and K Sullivan. 1991a. Aging Mechanisms in the Westinghouse PWR (Pressurized Water Reactor) Control Rod Drive System. BNL-NUREG-45748, Brookhaven National Laboratory, Upton, New York.

Gunther W and K Sullivan. 1991b. "Detecting and Mitigating Rod Drive Control System Degradation in Westinghouse PWRs." IEEE Transactions on Nuclear Science 38(6):1760-1765.

Haasl D, J Young and W Cramond. 1988. Probabilistic Risk Assessment Course Documentation. NUREG/CR-4350, U.S. Nuclear Regulatory Commission, Washington, D.C.

Haynes HD. 1990. "Evaluation of Check Valve Monitoring Methods." In Proceedings of the U.S. Nuclear Regulatory Commission, Seventeenth Water Reactor Safety Information Meeting, pp. 39-58. October 23-25, 1989, Rockville, Maryland. U.S. Nuclear Regulatory Commission, Washington, D.C.

Hines JW, J Garvey, J Preston and A Usynin. 2008. "Tutorial: Empirical Methods for Process and Equipment Prognostics." In 53rd Annual Reliability and Maintainability Symposium (RAMS), 2008 Proceedings. January 28-31, 2008, Las Vegas, Nevada.

Hudson B. 1999. "HV Motor Condition Monitoring-The End User's View." In IEE Colloquium Design, Operation and Maintenance of High Voltage (3.3 kV to $11 \mathrm{kV}$ ) Electric Motors for Process Plant, pp. 7/17/15. September 30, 1999, Glasgow, United Kingdom. DOI 10.1049/ic:19990823. IEE, London.

Jarrell DB, DR Sisk and LJ Bond. 2004. "Prognostics and Conditioned-Based Maintenance: A New Approach to Precursive Metrics." Nuclear Technology 145(3):275-286.

Jung JC and PH Seong. 2006. "An Improved Method for Reactor Coolant Pump Abnormality Monitoring Using Power Line Signal Analysis." Nuclear Engineering and Design 236(1):57-62.

Kafka P. 2008. "Probabilistic Risk Assessment for Nuclear Power Plants." In Handbook of Performability Engineering, pp. 1179-1192 ed: K Misra. Ch. 71. Springer London.

Koo IS and WW Kim. 2000. "The Development of Reactor Coolant Pump Vibration Monitoring and a Diagnostic System in the Nuclear Power Plant." ISA Transactions 39(3):309-316.

Korkua S, H Jain, W-J Lee and C Kwan. 2010. "Wireless Health Monitoring System for Vibration Setection of Induction Motors." In 2010 IEEE Industrial and Commercial Power Systems Technical Conference, I\&CPS 2010, pp. 1-6. May 9-13, 2010, Tallahassee, Florida. DOI 10.1109/ICPS.2010.5489899. IEEE, Piscataway, New Jersey.

Kothamasu R, SH Huang and WH VerDuin. 2006. "System Health Monitoring and Prognostics - A Review of Current Paradigms and Practices." The International Journal of Advanced Manufacturing Technology 28(9-10):1012-1024.

Lewis J. 1994. "Innovative Testing of Motor Operated Valves." In Proceedings of the 1994 Nuclear Science Symposium and Medical Imaging Conference, pp. 1098-1101 Vol.3. October 30-November 5, 1994, Norfolk, Virginia. DOI 10.1109/NSSMIC.1994.474652. IEEE, Piscataway, New Jersey. 
Lu CJ and WO Meeker. 1993. "Using Degradation Measures to Estimate a Time-to-Failure Distribution." Technometrics 35(2):161-174.

Lu CJ, WQ Meeker and LA Escobar. 1996. "A Comparison of Degradation and Failure-Time Analysis Methods for Estimating a Time-to-Failure Distribution." Statistica Sinica 6:531-546.

MacPherson H. 1985. "The Molten Salt Reactor Adventure." Nuclear Science and Engineering 90:374380 .

Maruthi GS and KP Vittal. 2005. "Electrical Fault Detection in Three Phase Squirrel Cage Induction Motor by Vibration Analysis using MEMS Accelerometer." In International Conference on Power Electronics and Drives Systems (PEDS 2005) pp. 838-843. November 28-December 1, 2005, Kualu Lumpur, Malaysia. DOI 10.1109/PEDS.2005.1619804. IEEE, Piscataway, New Jersey.

Maughan CV and JM Reschovsky. 2010. "Advances in Motor and Generator Rotor Health." In 2010 IEEE International Symposium on Electrical Insulation (ISEI 2010), pp. 1-4. June 6-9, 2010, San Diego, California. DOI 10.1109/ELINSL.2010.5549730. IEEE, Piscataway, New Jersey.

McDowell BK, JR Nickolaus, MR Mitchell, GL Swearingen and R Pugh. 2011. High Temperature Gas Reactors: Assessment of Applicable Codes and Standards. PNNL-20869, Pacific Northwest National Laboratory, Richland, Washington.

McShane JL and NH Ulerich. 1992. "System and Method for Valve Monitoring Using Pipe-Mounted Ultrasonic Transducers." Patent Number 5,115,672.

Nakamura T and M Terada. 1985. "Development of Leak Monitoring System for Pressurizer Valves." Progress in Nuclear Energy 15:175-179.

NERAC. 2002. A Technology Roadmap for Generation IV Nuclear Energy Systems - Ten Nations Preparing Today for Tomorrow's Energy Needs. GIF-002-00, U.S. DOE Nuclear Energy Research Advisory Committee (NERAC) and the Generation IV International Forum (GIF), Washington, D.C.

NRC. 1994. Preapplication Safety Evaluation Report for the Power Reactor Innovative Small Module (PRISM) Liquid-Metal Reactor. NUREG-1368, U.S. Nuclear Regulatory Commission (NRC), Washington, D.C.

NRC. 2012. Probabilistic Risk Assessment (PRA). U.S. Nuclear Regulatory Commission (NRC). Washington, D.C. Accessed October 17, 2012. Available at http://www.nrc.gov/about-nrc/regulatory/riskinformed/pra.html (last updated March 29, 2012).

OECD/NEA. 2004. RISK MONITORS: The State of the Art in their Development and Use at Nuclear Power Plants. NEA/CSNI/R(2004)20, Organisation for Economic Co-Operations and Development (OECD)/Nuclear Energy Agency (NEA), Committee on the Safety of Nuclear Installations, Paris, France.

Papazoglou IA. 1998. "Mathematical Foundations of Event Trees." Reliability Engineering \& System Safety 61(3):169-183.

Pázsit I and G Th Analytis. 1980. "Theoretical Investigation of the Neutron Noise Diagnostics of TwoDimensional Control Rod Vibrations in a PWR." Annals of Nuclear Energy 7(3):171-183. 
Prabhakaran A and CR Jagga. 1999. "Condition Monitoring of Steam Turbine-Generator through Contamination Analysis of Used Lubricating Oil." Tribology International 32(3):145-152.

Puglia WJ and B Atefi. 1995. "Examination of Issues Related to the Development and Implementation of Real-Time Operational Safety Monitoring Tools in the Nuclear Power Industry." Reliability Engineering \& System Safety 49(2):189-199.

Ramakrishnan A and MG Pecht. 2003. "A Life Consumption Monitoring Methodology for Electronic Systems." IEEE Transactions on Components and Packaging Technologies 26(3):625-634.

Reiss T, G Csom, S Fehér and S Czifrus. 2010. "The Simplified Supercritical Water-Cooled Reactor (SSCWR), a New SCWR Design." Progress in Nuclear Energy 52(2):177-189.

Rosenthal M, P Kasten and R Briggs. 1970. "Molten Salt Reactors-History, Status, and Potential." Nuclear Applications and Technology 8(2):107-117.

Rosenthal MW. 2009. An Account of Oak Ridge National Laboratory's Thirteen Nuclear Reactors. ORNL/TM-2009/181, Oak Ridge National Laboratory, Oak Ridge, Tennessee. Revised March 2010.

Saha B and K Goebel. 2011. "Model Adaptation for Prognostics in a Particle Filtering Framework." International Journal of Prognostics and Health Management 2(6).

Schwabacher M. 2005. "A Survey of Data-Driven Prognostics." In InfoTech at Aerospace: Advancing Contemporary Aerospace Technologies and Their Integration, pp. 887-891. September 26-29, 2005, Arlington, Virginia. American Institute of Aeronautics and Astronautics Inc., Reston, Virginia.

Schwabacher M and K Goebel. 2007. "A Survey of Artificial Intelligence for Prognostics." In Artificial Intelligence for Prognostics - AAAI Fall Symposium, pp. 107-114. November 9-11, 2007, Arlington, Virginia. American Association for Artificial Intelligence, Menlo Park, California.

Seker S, E Ayaz and E Turkcan. 2003. "Elman's Recurrent Neural Network Applications to Condition Monitoring in Nuclear Power Plant and Rotating Machinery." Enginering Applications of Artificial Intelligence 16:647-656.

Sharp ME. 2012. Prognostic Approaches Using Transient Monitoring Methods. Ph.D. Thesis, University of Tennessee, Knoxville, Tennessee. Available at http://trace.tennessee.edu/utk_graddiss/1431.

Thomson WT and M Fenger. 2001. "Current Signature Analysis to Detect Induction Motor Faults." IEEE Industry Applications Magazine 7(4):26-34.

Trutt FC, J Sottile and JL Kohler. 2002. "Online Condition Monitoring of Induction Motors." IEEE Transactions on Industry Applications 38(6):1627-1632.

Upadhyaya BR, M Naghedolfeizi and B Raychaudhuri. 1994. "Residual Life Estimation of Plant Components." P/PM Technology June:22-29.

Vesely W, F Goldberg, N Roberts and D Haasl. 1981. Fault Tree Handbook. NUREG-0492, U.S. Nuclear Regulatory Commission, Washington, D.C. 
Wallace CJ, GM West, GJ Jahn, SDJ MacArthur, D Towle and G Buckley. 2010. "Control Rod Monitoring of Advanced Gas-Cooled Reactors." In Seventh American Nuclear Society International Topical Meeting on Nuclear Plant Instrumentation, Control, and Human-Machine Interface Technologies. November 7-11, 2010, Las Vegas, Nevada. American Nuclear Society.

Weaver KD, JS Herring and PE MacDonald. 2001. "A Comparison of Long-Lived, Proliferation Resistant Fast Reactors." In International Conference on Back-End of the Fuel Cycle: From Research to Solution (GLOBAL 2001). Idaho National Engineering and Environmental Laboratory, Idaho Falls, Idaho. INEEL/CON-00-01618 PREPRINT. Available at http://www.inl.gov/technicalpublications/Documents/2813743.pdf.

Woloshun KA, V Watts and N Li. 2004. Lead-Bismuth Eutectic as Advanced Reactor Coolant: Operational Experience. LA-UR-04-3925, Los Alamos National Laboratory, Los Alamos, New Mexico.

Wu JS and GE Apostolakis. 1992. "Experience with Probabilistic Risk Assessment in the Nuclear Power Industry." Journal of Hazardous Materials 29(3):313-345.

Xu D and W Zhao. 2005. "Reliability Prediction Using Multivariate Degradation Data." In Annual Reliability and Maintainability Symposium (RAMS 2005), pp. 337-341. January 24-27, 2005, Alexandria, Virginia. IEEE, Piscataway, New Jersey.

Yan W and KF Goebel. 2003. "Sensor validation and fusion for gas turbine vibration monitoring."106117. $10.1117 / 12.487206$.

Yoshikawa H, M Yang, M Hashim, M Lind and Z Zhang. 2011. "Design of risk monitor for nuclear reactor plants." Nuclear Safety and Simulation 2(3):266-274. 



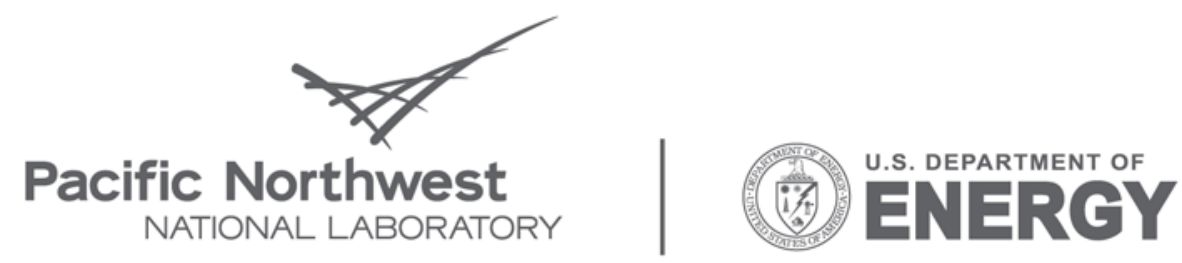

Proudly Operated by Battelle Since 1965

902 Battelle Boulevard

P.O. Box 999

Richland, WA 99352

1-888-375-PNNL (7665)

www.pnl.gov 